Article

\title{
Oscillating Wall Jets for Active Flow Control in a Laboratory Fume Hood-Experimental Investigations
}

\author{
Juergen Liebsch * and Christian Oliver Paschereit
}

check for

updates

Citation: Liebsch, J.; Paschereit, C.O. Oscillating Wall Jets for Active Flow Control in a Laboratory Fume Hood-Experimental Investigations. Fluids 2021, 6, 279. https://doi.org/ $10.3390 /$ fluids6080279

Academic Editor: Pier Marzocca

Received: 28 May 2021

Accepted: 26 July 2021

Published: 10 August 2021

Publisher's Note: MDPI stays neutral with regard to jurisdictional claims in published maps and institutional affiliations.

Copyright: (c) 2021 by the authors. Licensee MDPI, Basel, Switzerland. This article is an open access article distributed under the terms and conditions of the Creative Commons Attribution (CC BY) license (https:/ / creativecommons.org/licenses/by/ $4.0 /)$.
Chair of Fluid Dynamics-Hermann-Föttinger-Institute, Technical University Berlin, Müller-Breslau-Str. 8, 10623 Berlin, Germany; oliver.paschereit@tu-berlin.de

* Correspondence: juergen.liebsch@campus.tu-berlin.de

\begin{abstract}
Wall jets are applied to reduce flow separation and recirculation of the airflow entering the inner space of a laboratory fume hood through its front opening. The flow separation in the hood was further reduced by introducing a self-induced oscillatory motion using fluidic oscillators. The design of the oscillators integrated in the predetermined contour are based on numerical simulations. The effect of the steady and unsteady wall jet was investigated experimentally using flow visualization, particle image velocimetry (PIV), and containment measurements. The oscillatory wall-jet led to reduction of flow separation and recirculation even at lower injection volume flows. In consequence, the usage of fluidic oscillators for a laboratory fume hood increases the energy efficiency of the system without reducing the safety of the laboratory fume hood.
\end{abstract}

Keywords: fluidic oscillator; oscillating jet; wall jet; jet; flow control; fume hood; laboratory fume hood; containment capability; containment; flow visualization; PIV

\section{Introduction}

A Laboratory fume hood provides protection against toxic hazards when gases or dusts are released in its inner space and, thus, represents an important safety-related device for protecting the health of persons working in a laboratory.

The fume hood is connected to an external ventilation system that provides a flow through its inner space. The level of the extracted air flow rate is one of the most significant factors in determining the energy demand of the fume hood [1]. The principle of sustainability for resource utilization, which is becoming increasingly important in the establishment and operation of laboratories, is leading to a growing demand for fume hoods with high energy efficiency [2-4]. Since the containment capability is initially directly related to the level of the extracted air volume flow rate, a fume hood that requires a lower exhaust air volume flow rate to comply with the maximum permissible breakout values has a higher energy efficiency.

To ensure the best possible access to the workspace for a given external width, the fume hood investigated here is designed with slim side posts. This results in the flow being deflected at the side post in a narrow radius (significantly more than at the wider horizontal worktop profile), see Figure 1.

Due to the strong deflection of the flow at the streamlined side post [5], the pressure rise is so steep that the energy of the flow is insufficient to overcome it and, as a result, the flow detaches completely (Figure 2a). This forms a large recirculation bubble (Figure 2b) which is responsible for a reduced ability of the fume hood to contain hazardous gases and particles.

To improve the containment capability of the fume hood, the flow can be controlled either passively or actively. For passive control, e.g., the arrangement and size of the exhaust openings in the inner space of the fume hood are used [6]. Another possibility for passive control is offered by the shaping of the flow guiding components, in particular the frame profiles of the front opening [5-7]. 


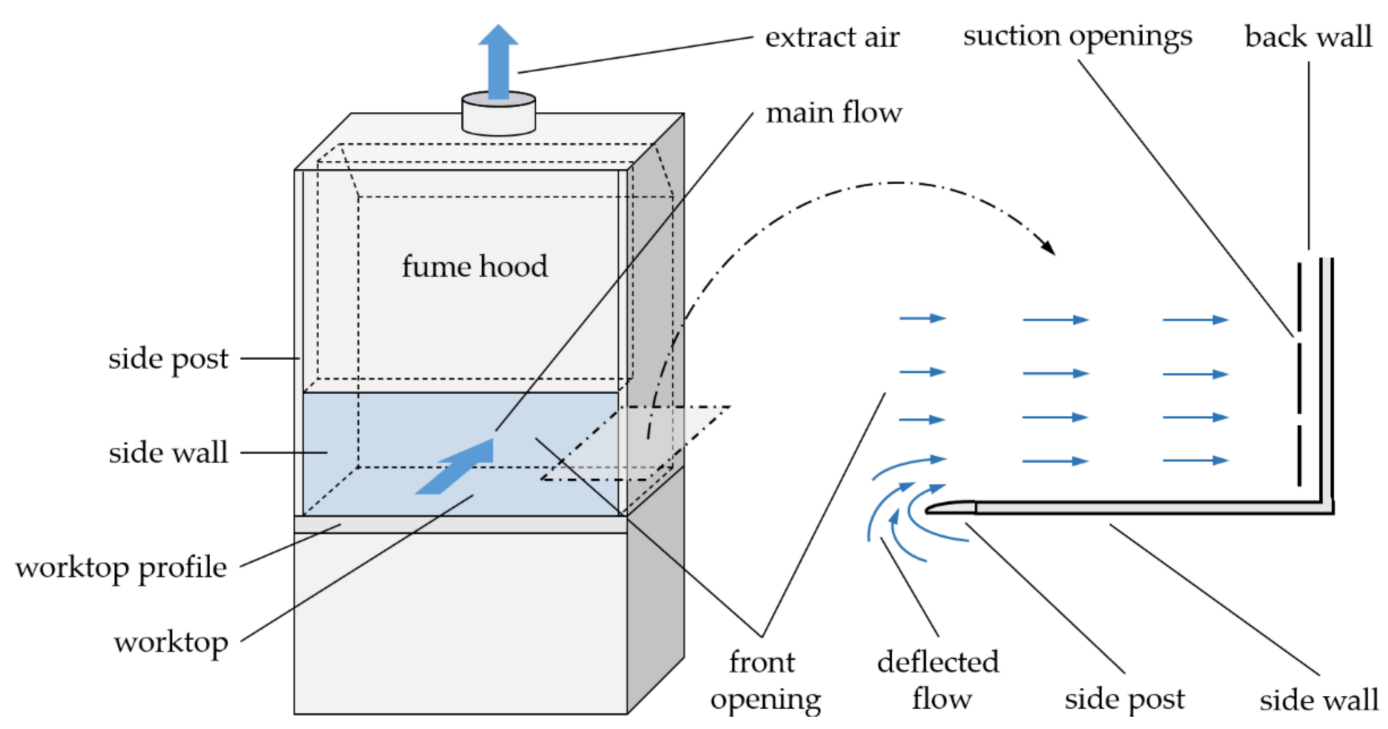

Figure 1. Fume hood with main components and flow deflection at the side post—schematic representation.

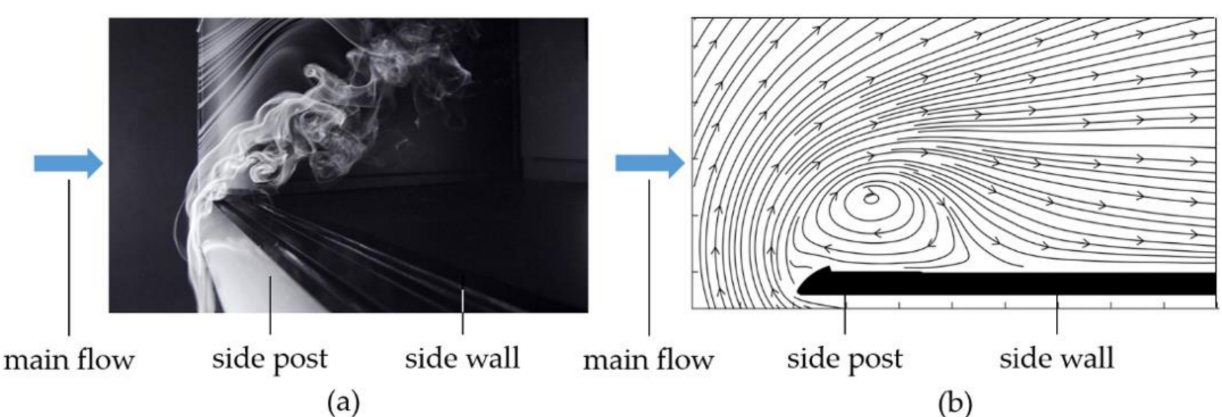

(a)

(b)

Figure 2. Flow separation and backflow at the side wall of the fume hood: (a) flow visualization with smoke wire technique and (b) streamlines deducted from PIV measurements.

Comparison of different designs of fume hoods shows that fume hoods with flow control using air jets require a lower extract air volume to ensure the required safety and are therefore more energy-efficient than those without air jets [8].

Known concepts for actively controlling the flow in fume hoods generally involve air jets which are placed in the inner space of the fume hood. A basic distinction can be made between jets introduced perpendicular to the main flow direction, which simply serve the purpose of an air curtain with a blocking effect [9-11], and jets introduced in the area of the front opening parallel to the wall, as in the fume hood investigated here, which have the primary objective of stabilizing the inlet flow in the front opening [12-15].

To reduce flow separation and recirculation in the fume hood investigated here and, thus, decrease the risk of outbreak of hazardous matter, flow control has been applied to the fume hood's sidewalls and worktop [14]. This is achieved using jets blown out of the frame profiles of the front opening, see Figure 3.

However, the intended effect of preventing flow separation and recirculation is only achieved to a limited extent [16]. The jets cause a significant reduction in the size of the recirculation area that can be observed without control (Figure 4a), as well as an increase in velocity in the area close to the wall. But the jet detaches from the sidewall about $150 \mathrm{~mm}$ downstream of the leading edge of the side post. Downstream of the detachment point, the velocity in the near-wall flow region is similarly low as in the fume hood with no jets, see Figure $4 b$. 


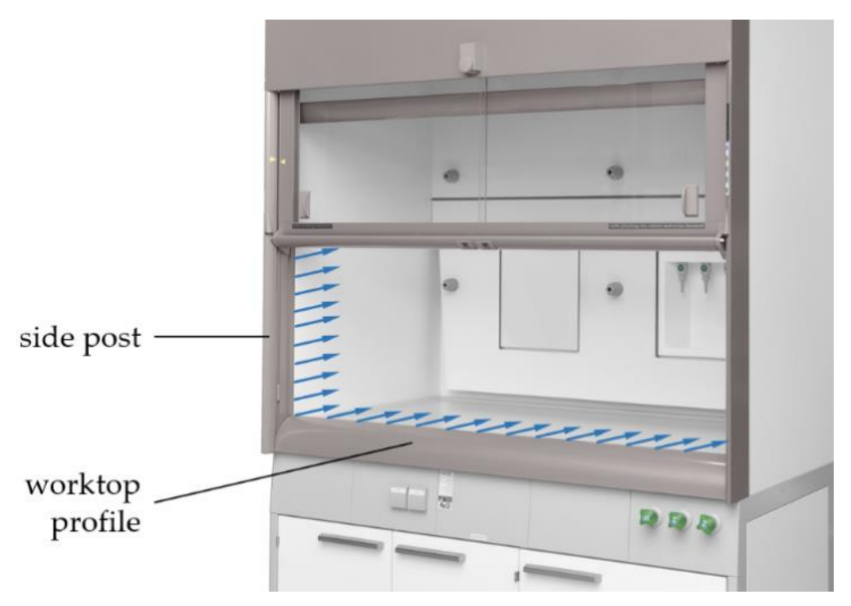

Figure 3. Wall jets blowing out of the frame profiles of the front opening—schematic representation.

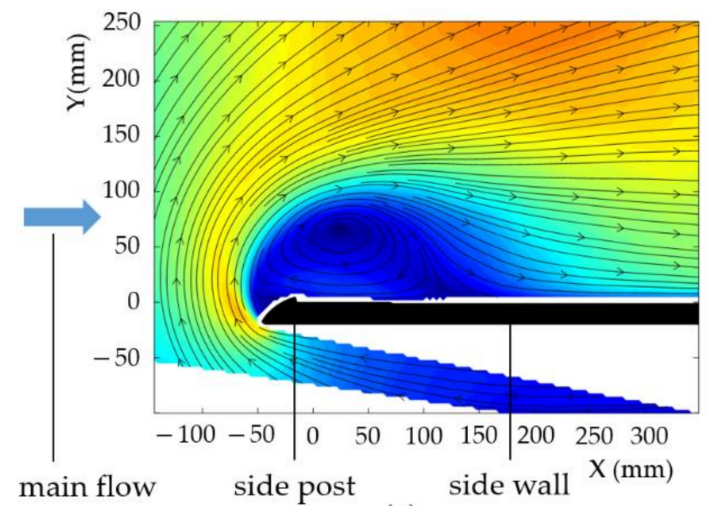

(a)

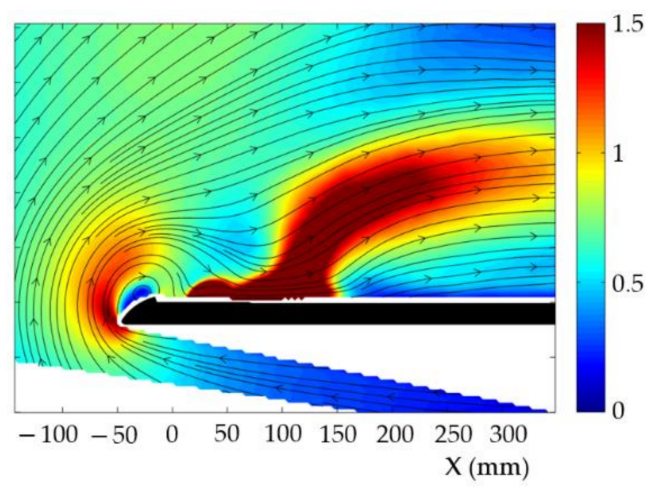

(b)

Figure 4. Flow separation at the side wall of the fume hood: (a) conventional fume hood with no active control and (b) investigated baseline fume hood with wall jets. Diagrams from PIV-Measurements: Sectional streamlines of the mean flow field in the measuring level and contours of the three-dimensional velocity magnitude normalized by the mean inflow velocity.

Due to the air jets placed in the inner space of the laboratory fume hood, the average face velocity in the front opening is reduced by the amount resulting from the jet volume flow rate at a constant extract volume flow rate. Since the containment capability in a fume hood is initially a function of the face velocity in the front opening [17], the goal is to achieve the effect of the wall jets with the lowest possible jet volume flow. This increases the probability that the (positive) effect of the jets on improving containment will be higher than their (negative) effect of reducing the average face velocity in the front opening for a given extract volume flow rate.

In this study, we have attempted in a first step to prevent the detachment of the jet from the sidewall shown above while simultaneously reducing the jet volume flow by modifying the shape and arrangement of the jet nozzles.

In the second, more far-reaching step, the effect of oscillating jets is investigated. The idea of using oscillating air jets in the fume hood is based on the finding in several studies (e.g., [18]) that with oscillating jets a comparable effect on the prevention of detachment and recirculation can be already achieved at a smaller momentum coefficient than with steady jets. With the same main flow, it allows for a further reduction in the jet volume flow rate and thus a further reduction in the energy required for jet generation, as well as a smaller effect on the inflow velocity in the front opening, which influences the retention capability of the fume hood, at a constant exhaust air volume flow rate. The design of the oscillators 
integrated into the frame profiles of the fume hood is carried out with the support of a computational fluid dynamics (CFD) simulation and validated with experiments.

\section{Flow Control in the Fume Hood}

\subsection{Steady Blowing Jets}

The separation and recirculation of the flow, which can be observed with no flow control and which affects the containment capability of the fume hood, should be suppressed by the use of wall jets located in the area of the front opening [12].

The jet air introduced into the fume hood is taken from the same immediate environment as the exhaust air flowing through the inner space of the fume hood. This means that the jet air and the ambient air have the same temperature, isothermal jets are present, and no buoyancy or downward forces act on the horizontally emitted jets.

Basically, the shape and development of the jet is influenced by the geometry of the jet exit opening. For stability and manufacturing reasons, the side post profile cannot be provided with a continuous slot in the fume hood investigated here; this must be replaced by rectangular nozzle openings with a height of $2 \mathrm{~mm}$ and a width of $30 \mathrm{~mm}$. Fixed ridges with a width of $10 \mathrm{~mm}$ remain between the individual outlet openings. The side post profile is designed as a settling chamber, so that air jets emerge through slit-shaped nozzle openings into the inner space of the fume hood, see Figure 5.

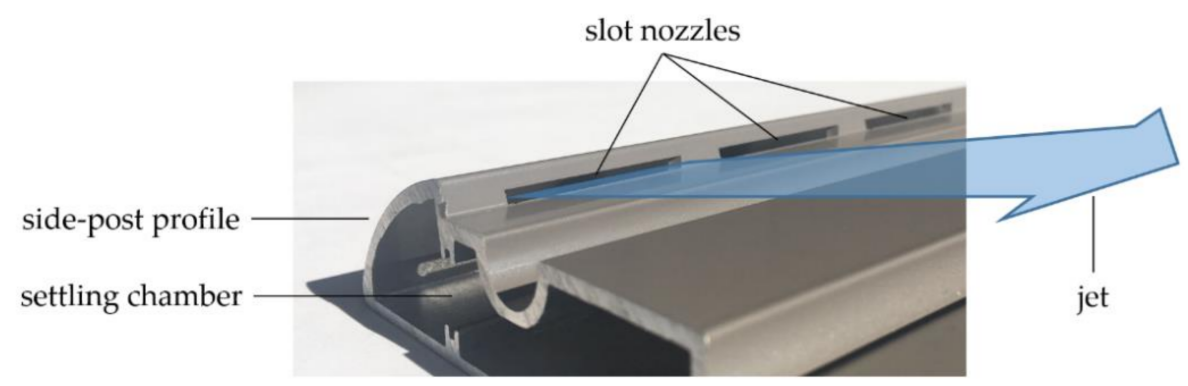

Figure 5. Slot-shaped jet exit openings on the side post, baseline fume hood. Photography of the cut-open hollow aluminum profile. Jet shown schematically.

According to Rietschel and Esdorn [19], the jets arranged side-by-side mix with increasing distance to the exit openings to form a single jet.

In addition to the cross-section of the exit opening, the jet development is also determined by the length and orientation of the nozzle. It is known that the guide ratio $\mathrm{F}$ of the nozzle should not fall below a minimum value, which is between 3 and 5 , in order to give direction to the jet.

$$
F=\frac{l}{D_{h}}
$$

where $l$ is the length and $D_{h}$ is the hydraulic diameter of the nozzle.

For technical reasons, the length of the nozzle in the baseline fume hood is only $2 \mathrm{~mm}$ (Figure 6), resulting in a guide ratio of $F=0.5$.

In addition to the length of the nozzle, its orientation also influences the jet development. In the baseline fume hood, the jet exit angle to the side wall is $\beta=25^{\circ}$ (Figure 6). Insights into the effects of the jet exit angle on the development of the approach behavior of a plane wall jet can be derived from the investigations of Nasr and Lai [20]. Their results show that for an exit angle to the wall of $\beta=15^{\circ}$, the assumed jet axis approaches the wall soon after exit, while convergence of the jet axis with the wall at an exit angle of $\beta=30^{\circ}$ no longer occurs in the measured field.

For the reasons explained above, the combination of a low guide ratio and a (too) large angle of the jet axis to the wall in the baseline fume hood means that the jets emerging from the side post profile are not wall jets, but free jets. This also explains the results of the PIV measurements shown in Figure 3-separation of the jet from the side wall. 


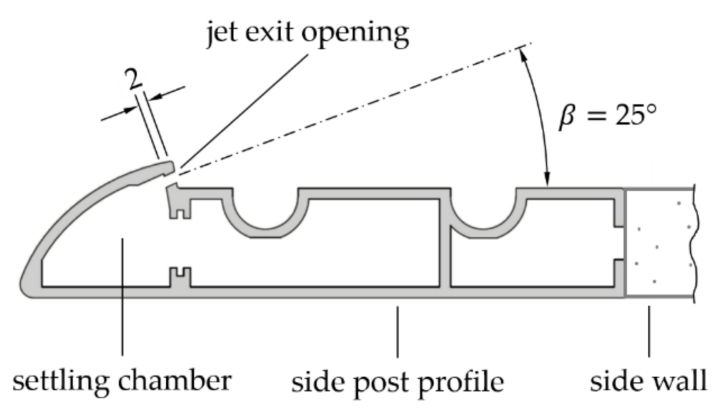

Figure 6. Jet exit at the side post profile, baseline fume hood, sectional drawing.

In addition to preventing flow separation and recirculation, there is a secondary effect that is to be achieved with the help of the jets applied to the front opening. In a conventional fume hood (with no flow control), the velocity of the flow decreases outward due to wall friction. This results in reduced removal of gaseous or particulate substances from near the wall. If the jets blowing out in the front opening are designed as wall jets, they improve the removal of pollutants near the wall on the direct path to the suction openings in the rear wall, as earlier investigations with visualized flow have shown [21].

In order to ensure that the jet is aligned with the side wall as intended as a wall jet, the side post profile of the baseline fume hood is modified with nozzle inserts that reduce the previous jet exit angle $\beta$ from $25^{\circ}$ to $5^{\circ}$ and increase the length of the nozzle $l$ from 2 to $14 \mathrm{~mm}$, see Figure 7.

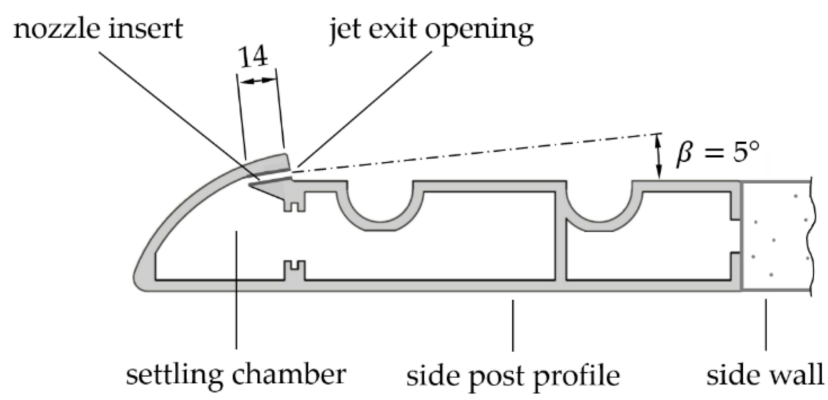

Figure 7. Side post profile with nozzle inserts to reduce the jet exit angle $\beta$ and increase the guide ratio $F$-sectional drawing.

Air jets blowing out in the fume hood have the disadvantage that (at a constant extract air volume flow rate) they reduce the volume flow rate flowing into the fume hood from the environment and, thus, the face velocity in the front opening. Since the containment capability in a conventional fume hood is initially a function of the face velocity in the front opening [17], it must be achieved that the (positive) effect of the air jets, in particular the prevention of flow separation and recirculation in the fume hood and, thus, an improvement of its containment capability, is greater than their (negative) effect by reducing the face velocity in the front opening. This results in the objective of achieving the effect of the wall jets with the lowest possible jet volume flow.

To determine the effectiveness of blowing air jets for separation control, PoissonQuinton proposed the momentum coefficient $C_{\mu}$.

$$
C_{\mu}=\frac{\rho \cdot c_{0}^{2} \cdot A_{0}}{0,5 \cdot \rho \cdot u^{2} \cdot A_{W}}
$$

where $\rho$ is the density of the fluid, $A_{0}$ is the flow-through area at the jet outlet, $c_{0}$ is the jet exit velocity, $u$ is the velocity of the stream, and $A_{W}$ is the area of the sidewall of the fume hood. 
For the baseline fume hood, $C_{\mu}=2.25$. Although, at first glance the flow around the side post with the connected side wall (Figure 1) shows a certain similarity to an aircraft wing, $C_{\mu}$ here is significantly higher than has been determined in investigations on wing airfoils (e.g., [18,22]). This can be attributed to a larger reference area $A_{0}$ (entire sidewall) used as a basis in the laboratory fume hood as well as to the significantly smaller Reynolds number of $\operatorname{Re}<10,000$ of the flow in the laboratory fume hood. The measures described in the following to improve the effectiveness of the wall jets are based on the momentum coefficient of the baseline design.

In addition to the length and direction of the nozzle, there are further parameters that influence the effectiveness of the jets, for example the position and number of outlets. While for the design of new wall-mounted jet nozzles the position of the exit openings cannot be changed in the direction of flow due to the given design of the side post profile, the nozzle cross-section and the number of exit openings are used for this purpose. With the aim of keeping the jet volume flow rate for the fume hood as low as possible, the cross-sectional area of the individual nozzle is reduced. At the same time, the jet exit velocity $c_{0}$ is increased from $2.87 \mathrm{~m} / \mathrm{s}$ in the baseline to $10 \mathrm{~m} / \mathrm{s}$ in order not to weaken the momentum of the individual jets excessively. A velocity of $10 \mathrm{~m} / \mathrm{s}$ is chosen because higher jet exit velocities can lead to unwanted disturbing noise, as shown by preliminary experimental investigations in this study. The number of individual nozzles for the entire fume hood is increased from 72 to 131 in order not to increase the distances between the individual nozzles too much and thus to ensure that the individual jets continue to merge into an overall jet. From the design data described above, the momentum coefficient $C_{\mu}$ for the improved nozzles is reduced from 2.25 to 1.78. Because of the expected change from free jet to wall jet, an improved overall effect is nevertheless assumed. The jet volume flow $\dot{S}$ for the entire fume hood is reduced from 48 to $14.1 \mathrm{~m}^{3} / \mathrm{h}$. The higher pressure loss of the improved nozzles due to the higher jet exit velocity can be neglected in the energy balance for generating the jets in view of the considerable reduction in the jet volume flow to only $30 \%$ of the initial value.

\subsection{Oscillating Jets}

Examples of oscillating jets can be found in a wide variety of technical applications: In mixture improvement in combustion engines [23-25], controlling flow separation on airfoil profiles [26], boundary layer control in turbomachinery [27], controlling flow separation on compressor impellers [28], reducing the drag of trucks [29], or in reducing noise generated by the flow over a cavity [30].

Ostermann et al. [31] concluded from their quantitative analysis of the properties of a spatially oscillating jet that it has significantly better mixing properties compared to a conventional free jet. His investigations show that the oscillating jet exhibits a stronger entrainment effect as well as affects a larger area downstream than a steady jet and that dominant vortices directed in the flow direction are present in the flow field of the jet. Here it is assumed that these vortices are a cause of the high effectiveness of oscillating jets in controlling the flow.

Oscillating jets can be generated by means of moving mechanical components or by fluidic oscillators. The development history of fluidic oscillators dates back to the 1950s and they are becoming increasingly important, especially in the field of active flow manipulation. Gregory and Tomac [32] provide a comprehensive overview of the development of fluidic oscillators and their various applications.

Depending on their design, fluidic oscillators generate pulsating or sweeping jets. An illustrative description of the internal fluidic processes leading to oscillation of various designs of fluidic oscillators can be found in Bobusch et al. [33].

If a fluidic oscillator consisting of a mixing chamber and two feedback channels, as shown in Figure 8, is provided with a constant fluid supply, the incoming flow will attach to one side of the mixing chamber. A small part of the main flow returns to the inlet via the feedback channel located on the side of the adjacent flow. At this point, the flow 
exiting the feedback channel causes the main stream to detach from the wall and contact the opposite wall-where the process repeats by filling the recirculation area. In this way, a self-sustaining oscillation is created and an oscillating jet at the exit. To illustrate this, the flow pattern after the jet exit into the free environment can be seen in the photo on the right in Figure 8 when water is used as the fluid.

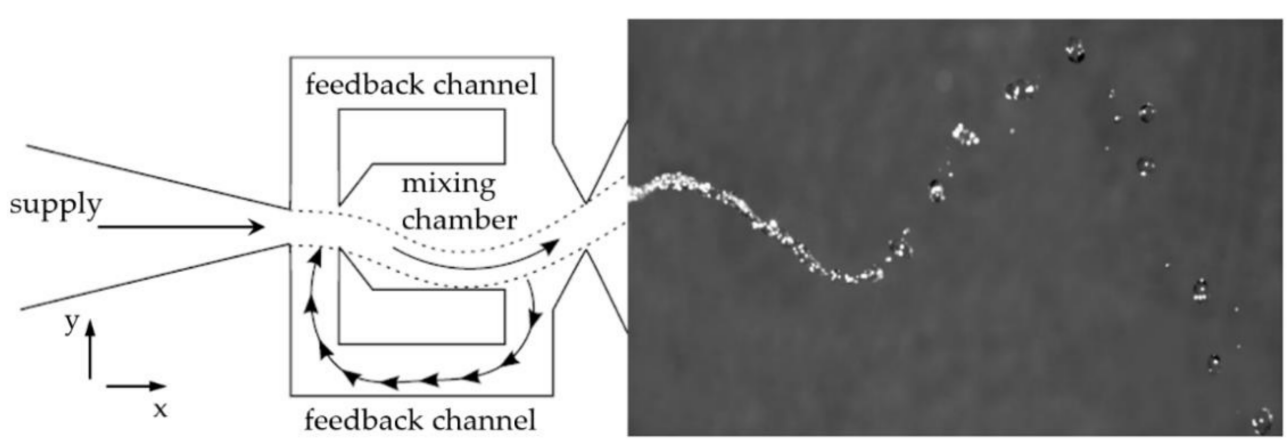

Figure 8. Working principle of a fluidic oscillator according to [34].

The main advantage of fluidic oscillators is that they do not require any moving mechanical or electrical components. In consequence, they are inexpensive to manufacture and (theoretically) free of wear and maintenance. At least for this reason, this design is particularly well suited to the present application in the fume hood.

In order to avoid flow noise, a jet exit velocity of $c_{0}=10 \mathrm{~m} / \mathrm{s}$ is selected for the design of the fluidic oscillator (as was already the case with the improved nozzles with steady outflow). An important parameter influencing the effectiveness of the separation control is the oscillation frequency [18]. The oscillation frequency is influenced by the dimensions of the oscillator. Since the fluidic oscillator has to be completely integrated into the contour of the side post (Figure 7), its size and thus also its oscillation frequency are predetermined within a narrow range.

The design of the fluidic oscillator for the fume hood was realized with the support of FDX Fluid Dynamix GmbH. On the basis of the geometric boundary conditions, the contour shown in Figure 9 is obtained and was designed for an oscillation frequency of $F_{O}=246 \mathrm{~Hz}$. A comparison of this frequency with FDX data from comparable applications suggests that the fluidic oscillator will perform as expected.

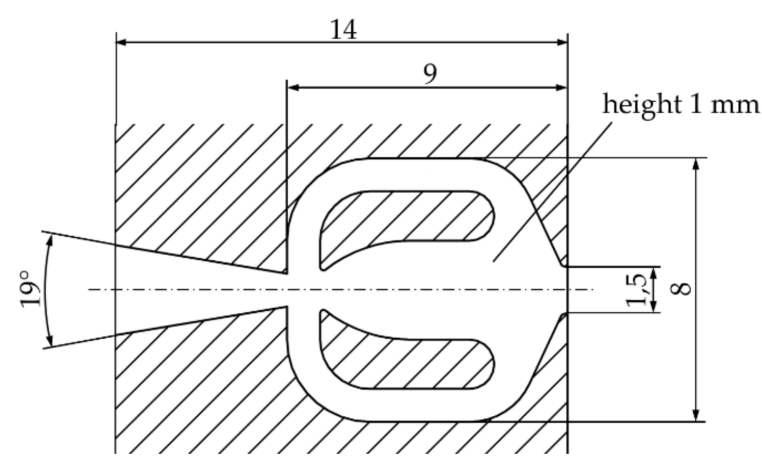

Figure 9. Main dimensions and internal contour of the fluidic oscillator for the fume hood.

The oscillators are integrated in the vertical side post profile and in the horizontal inflow profile at the front edge of the worktop in the same way as the nozzle inserts for steady blowing jets described in the previous section. The deflection of the jets emerging from the oscillators oscillating perpendicular to the main flow direction, relative to the side wall, is shown schematically in Figure 10. 


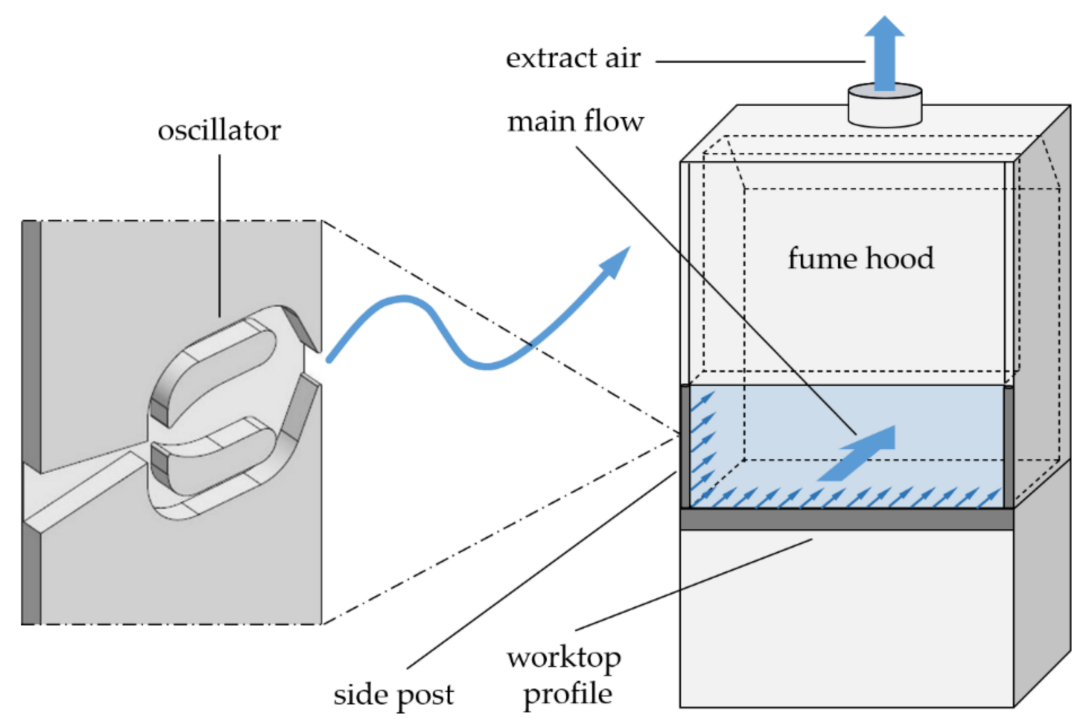

Figure 10. Orientation of oscillators integrated in the frame profiles of the front openingschematic representation.

Assuming that oscillating jets achieve a comparable separation and recirculation prevention effect with a smaller momentum coefficient than steady jets, the arrangement and number of nozzles are adopted from the design of the improved nozzles described in the previous section. Due to the smaller jet exit cross-section of the oscillators, this reduces the momentum coefficient $C_{\mu}$ from 1.78 to 0.89 . This design results in a further reduction of the jet volume flow rate $\dot{S}$ for the entire fume hood from 14.1 to $6.8 \mathrm{~m}^{3} / \mathrm{h}$. The higher energy input required to generate the oscillation compared to the steady outflow can be neglected in the energy balance for generating the jets given the considerable reduction in jet volume rate (to only $14 \%$ of the baseline and $48 \%$ of the improved nozzles with steady outflow).

\section{Numerical Simulation}

The time and cost required for the dimensionally and shape-accurate production of the proposed new nozzle shapes suggests that, as a first step, a numerical flow simulation should be carried out in the sense of a feasibility study before the experimental investigations. The aim is to assess the (improved) effect of the proposed nozzle designs with continuous discharge and with oscillating discharge in direct comparison with the baseline, taking into account the geometric and fluid mechanical conditions prevailing in the fume hood.

\subsection{CFD Model and Boundary Conditions}

The geometry model of the fume hood is created based on the CAD design data of the manufacturer of the baseline fume hood.

The structure of the mesh covering the flow geometry is generated using ANSYS ICEM 14.5.7. The mesh is unstructured with tetrahedral elements (Octree algorithm) and local refinements at points where large gradients have to be expected. Boundary layers are resolved by a boundary layer refinement (prism layer), which are parallel to the surface.

For the turbulence model, the SST (Shear Stress Transport) model implemented by Menter [35] at ANSYS is used. As it was shown in a previous study that this model is suitable for the simulation of fluidic devices [36]. For the ambient conditions, an air temperature of $25^{\circ} \mathrm{C}$ and a mean velocity of the base flow in the fume hood of $\bar{u}=0.25 \mathrm{~m} / \mathrm{s}$ are assumed.

Inlet boundary conditions for nozzles with steady discharge:

$$
u=c_{0}
$$


where $u$ is the velocity in $x$-direction and $c_{0}$ is the jet exit velocity: 0,4 , and $10 \mathrm{~m} / \mathrm{s}$.

Inlet boundary conditions for nozzles with oscillating discharge:

$$
\begin{gathered}
u=\sqrt{c_{0}^{2}-v^{2}} \cdot \cos \beta \\
v=c_{0} \cdot \sin \alpha \cdot \sin (2 \pi f \cdot t) \\
w=\sqrt{c_{0}^{2}-v^{2}} \cdot \sin \beta
\end{gathered}
$$

where $t$ is the time (s), $f$ is the oscillation frequency $(246 \mathrm{~Hz}), c_{0}$ is the jet exit velocity $(4$ and $10 \mathrm{~m} / \mathrm{s}), u$ is the velocity in $x$-direction $(\mathrm{m} / \mathrm{s}), v$ is the velocity in $y$-direction $(\mathrm{m} / \mathrm{s}), w$ is the velocity in $z$-direction $(\mathrm{m} / \mathrm{s}), \alpha$ is the maximum deflection of the oscillating jet $45^{\circ}$, and $\beta$ is the jet exit angel to the wall $10^{\circ}$.

The three-dimensional reference system of the wall jets blowing out of the side post profile is shown in Figure 11.

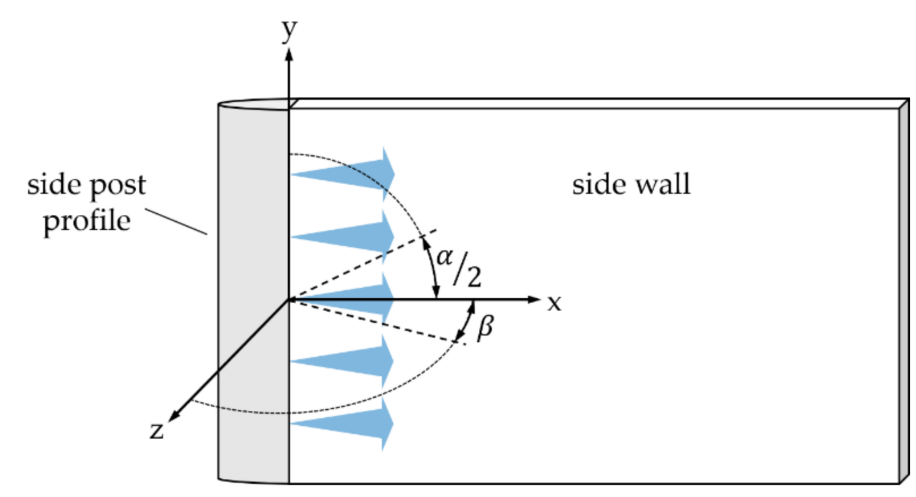

Figure 11. Three-dimensional reference system for the wall jets blowing out of the side post profileschematic representation.

The simulation starts with a steady-state initial calculation whose results are used for the subsequent transient calculation. This is done with an adaptive time step, keeping the Courant number CFL below 0.2. If the Courant number is larger than 1, information is transported through a cell of the lattice faster than it is resolved in a time step. This results in propagating and amplifying numerical errors, which should be avoided.

\subsection{Conclusions from Numerical Modeling}

In the conventional fume cupboard, which has the identical geometry of the flowguiding components as the fume hood with flow control, but in which no wall jets are discharged, the flow cannot follow the contours of the side post and detaches already at the leading edge with the formation of a pronounced recirculation area. The streamlines somewhat more distant from the side wall (outside the recirculation region) move away from the wall at an angle of about $10^{\circ}$ before approaching the side wall again about $400 \mathrm{~mm}$ downstream of the leading edge, see Figure 12a.

The larger recirculation area observed without flow control is changed into two much smaller recirculation areas by the wall jets with steady discharge. The first is located just downstream of the leading edge in the curved region of the side post, and the second is located on the side wall, about $300 \mathrm{~mm}$ downstream of the leading edge. The somewhat more distant streamlines (outside the recirculation areas) are almost parallel to the sidewall, see Figure 12b.

The oscillating wall jets reduce the size of the two recirculation regions created with steady discharge. In particular, the second recirculation region further downstream has almost completely disappeared. The somewhat more distant streamlines (outside the recirculation areas) approach the side wall downstream, see Figure 12c. 


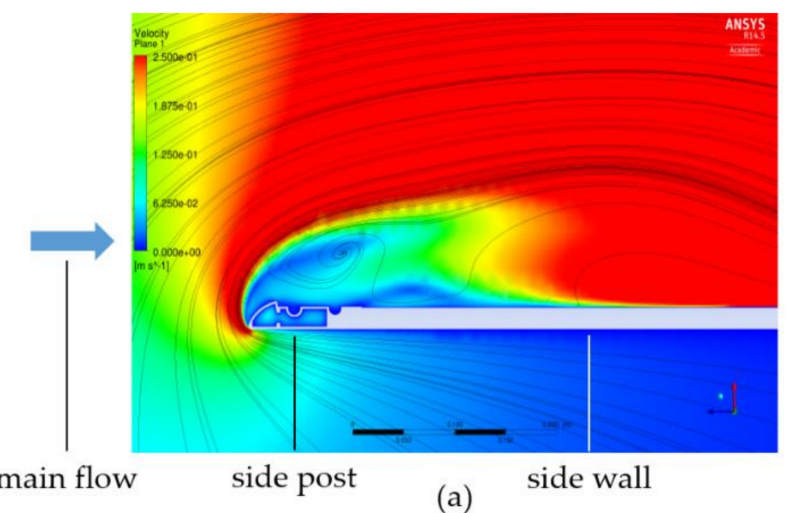

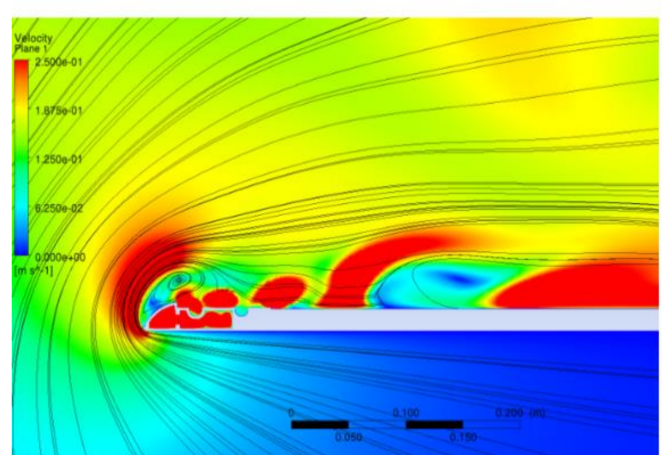

(b)

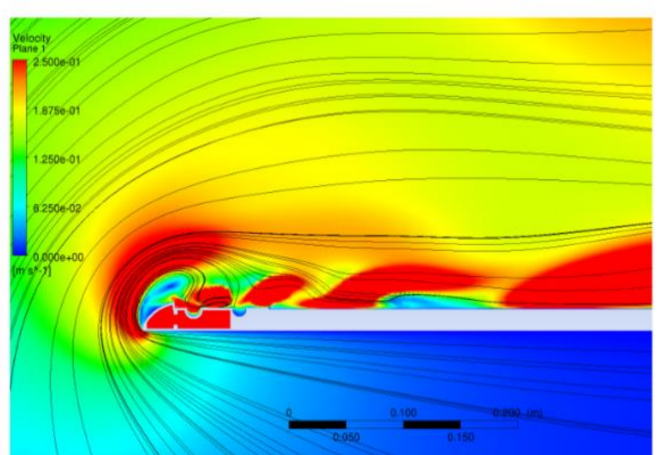

(c)

Figure 12. Flow in the area of side post and side wall. Diagrams with sectional streamlines of the mean flow field in a horizontal level and contours of the three-dimensional velocity magnitude normalized by the mean inflow velocity: (a) without wall jets; (b) steady wall jets $\left(\dot{S}=14.1 \mathrm{~m}^{3} / \mathrm{h}\right)$; and (c) oscillating wall jets $\left(\dot{S}=6.8 \mathrm{~m}^{3} / \mathrm{h}\right)$.

In the diagrams shown in Figure 12, the streamlines lie in a horizontal sectional plane passing $250 \mathrm{~mm}$ above the worktop through the side post and the side wall of the fume hood, and in the designs with wall jets through the center of a nozzle opening.

According to the results of the numerical simulation, it is obvious that the discharge of wall jets does not completely suppress the detachment and pronounced recirculation occurring in the fume cupboard without flow control, but it largely suppresses it, thus reducing the risk of backflow and pollutant outbreak. When evaluating the steady discharging jets in comparison to the oscillating jets, the respective energy requirement for jet generation must be taken into account. One measure of the energy required to generate the jets is the jet momentum. The jet volume flow for the entire fume hood is $\dot{S}=14.1 \mathrm{~m}^{3} / \mathrm{h}$ in the steady discharge nozzle version and $\dot{S}=6.8 \mathrm{~m}^{3} / \mathrm{h}$ in the oscillating discharge version. In both cases, the jet discharge velocity is $c_{0}=10 \mathrm{~m} / \mathrm{s}$, from which it follows that the jet momentum in the oscillating design is $52 \%$ smaller than in the steady discharge. It follows that the nozzle design with oscillating wall jets is clearly superior to the steady design.

\section{Experimental Setup}

\subsection{Flow Visualization}

The aim of the flow visualization experiments described here is to qualitatively assess the effects of controlling the flow in the fume hood, and in particular the improved effect of the proposed new nozzle designs. The method of visualization used here with the aid of a smoke wire makes it possible to observe the flow through the interior of the fume hood, flow separation with the formation of vortex structures in the inlet area of the front opening, and the direction and propagation of the air jets blowing out-the result is directly visible and can be captured quickly and intuitively.

Of the various known methods for flow visualization, the smoke wire technique is particularly well suited for the fume hood with its low velocity of the base flow. It makes 
it possible to visualize the flow field in an original fume hood without affecting the flow. Experimental parameters such as extract air volume flows or jet velocities can be changed during the experiment without having to intervene in the experimental setup.

The smoke wire device was developed on the basis of the smoke wire method presented by the "improved smoke wire flow visualization technique" of Dol et al. [37]. The operating principle of the smoke wire device is shown in Figure 13.

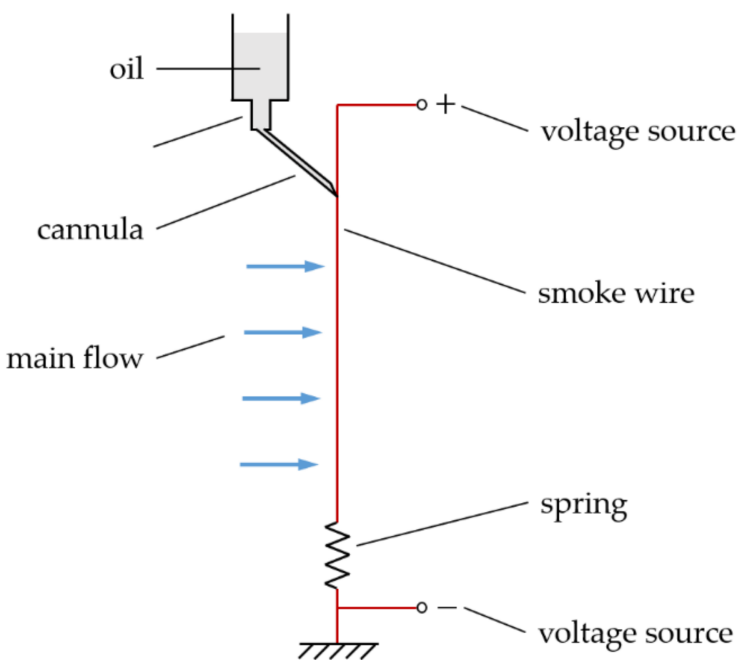

Figure 13. Principle of the smoke wire flow visualization technique.

By applying an electrical voltage, a vertically clamped thin wire is heated. Small drops of a suitable low-viscosity oil running down the wire by gravity are vaporized and carried along by the flow as (visible) very small condensate droplets. With the aid of a dosing device (throttle), the timing and spacing of the droplets running down the smoke wire can be adjusted in such a way that either individual sweep lines become visible or these sweep lines lie so close together that they appear to the observer as a closed surface.

The smoke wire used can be considered as a circular cylinder with a diameter of $d=0.1 \mathrm{~mm}$ flowing around it. With an average face velocity in the plane of the sash opening of the fume hood of $\mathrm{u}=0.2 \mathrm{~m} / \mathrm{s}$, the Reynolds number is $R e=1$. At this small Reynolds number, no vortices form, the flow around the wire is laminarly, an important requirement for disturbance-free flow visualization.

The smoke wire device allows the flow field in the fume hood be visualized in a (vertical) plane without affecting the flow. The arrangement of the smoke wire device shown in Figure 14 shows the fume hood in its normal, upright position. Since the smoke wire must always be clamped vertically, the fume hood must be set up lying on its side, rotated by $90^{\circ}$, for visualization of the flow field in the area of the side posts and the side walls.

The light source used to illuminate the smoke plane is an important component of the smoke wire device; for the experimental setup on the fume hood, an open area Tungsten emitter, Arri $1000 \mathrm{~W}$, with a stepped lens and a color temperature of $3200 \mathrm{~K}$ was used. The scattered light is caused by Mie scattering, which occurs when the illuminated particles are larger than the wavelength of the incoming light.

To increase the contrast to the white illuminated smoke particles and to avoid disturbing light reflections, the entire interior of the fume hood was lined with matte black foil and all visible frame profiles in the area of the front opening were painted matte black.

In order to obtain more information about the discharge angle and the mixing of the jet with the ambient, the wall jets blowing out of the side post profiles were investigated by means of fog visualization. For this purpose, a fog generator was used which, due to its small dimensions, could be completely integrated into the distributor housing of the jet air supply, see Figure 15. 


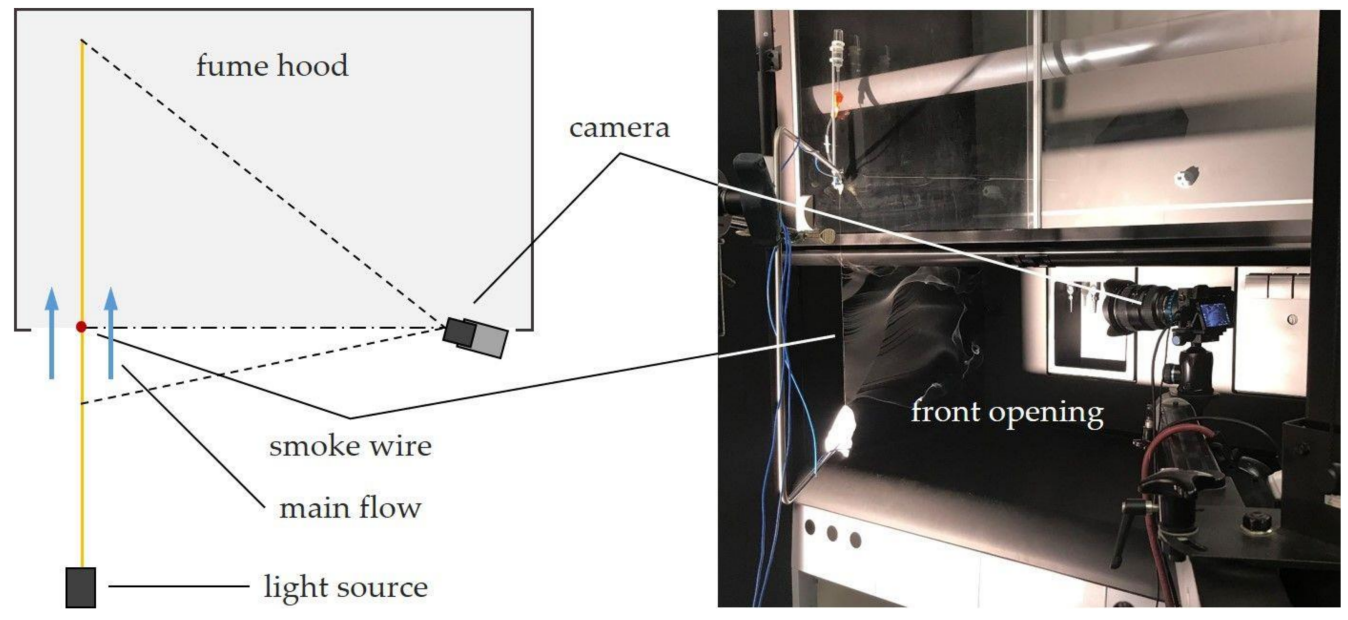

Figure 14. Experimental setup for flow visualization with the smoke wire.

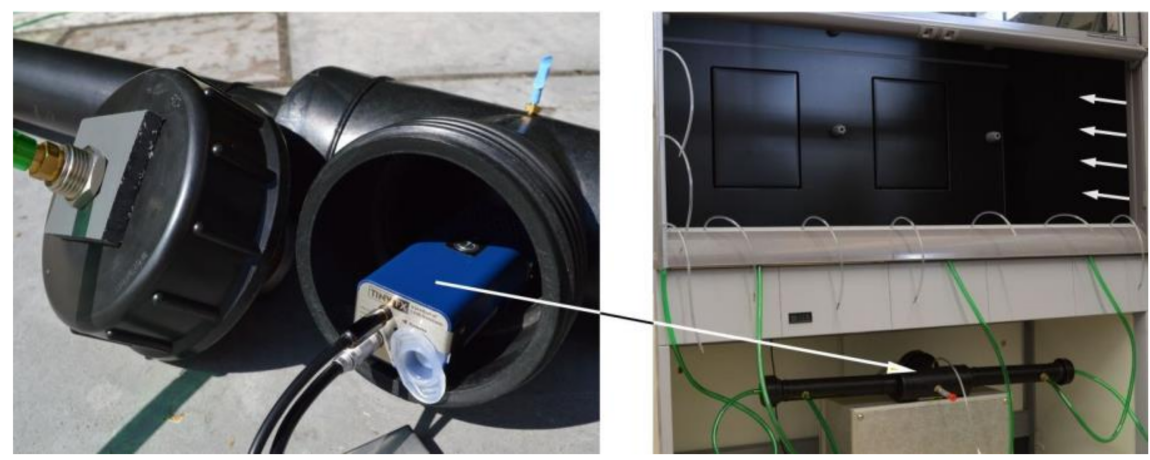

Figure 15. Experimental setup for visualizing the jet flow direction. Installation of the mini fog generator in the jet air distributor housing.

The fog generator is equipped with a radio remote control so that the fog generation can be switched on and off at any time without having to intervene in the experimental procedure. A glycol-based fluid is evaporated and condenses into fog as it exits a fog nozzle. The device has a uniform fog output within the pressure chamber of the jet air distributor, the momentum of which does not affect the jet development due to the sufficiently large volume of the pressure chamber and the distance upstream from the jet nozzles. All flow visualization experiments were carried out in a flow-calming hall with a floor area of $225 \mathrm{~m}^{2}$ and a room height of $6.50 \mathrm{~m}$.

A Sony A 3600 digital video camera, chip format APSC was used to capture the flow images. The shutter speed was $1 / 500 \mathrm{~s}$ and 25 frames were taken per second. For each setting, video films with a duration of 20 to $30 \mathrm{~s}$ were recorded. For evaluation, 30 frames taken in sequence are taken from the video films. These individual images are projected on top of each other, so that a mean value image is created in each case, which makes the flow course in the observed area clearly recognizable and illustrates it vividly.

\subsection{Particle Image Velocimetry (PIV)}

Particle Image Velocimetry (PIV) is suitable for investigating and analyzing flow separation and the effect of the wall jets blowing out to influence the flow in the fume hood.

Since the measuring plane is viewed with two cameras from different angles, a threedimensional image is produced in which all three velocity components can be determined. This method, known as stereo PIV, is suitable for the task at hand, since a perpendicular arrangement of the camera to the measurement plane (as required for the mono PIV 
method) would only be possible with restrictions due to the geometric conditions in the fume hood.

The experimental setup for the measurements on the side post and the subsequent side wall of the fume hood is shown schematically in Figure 16.

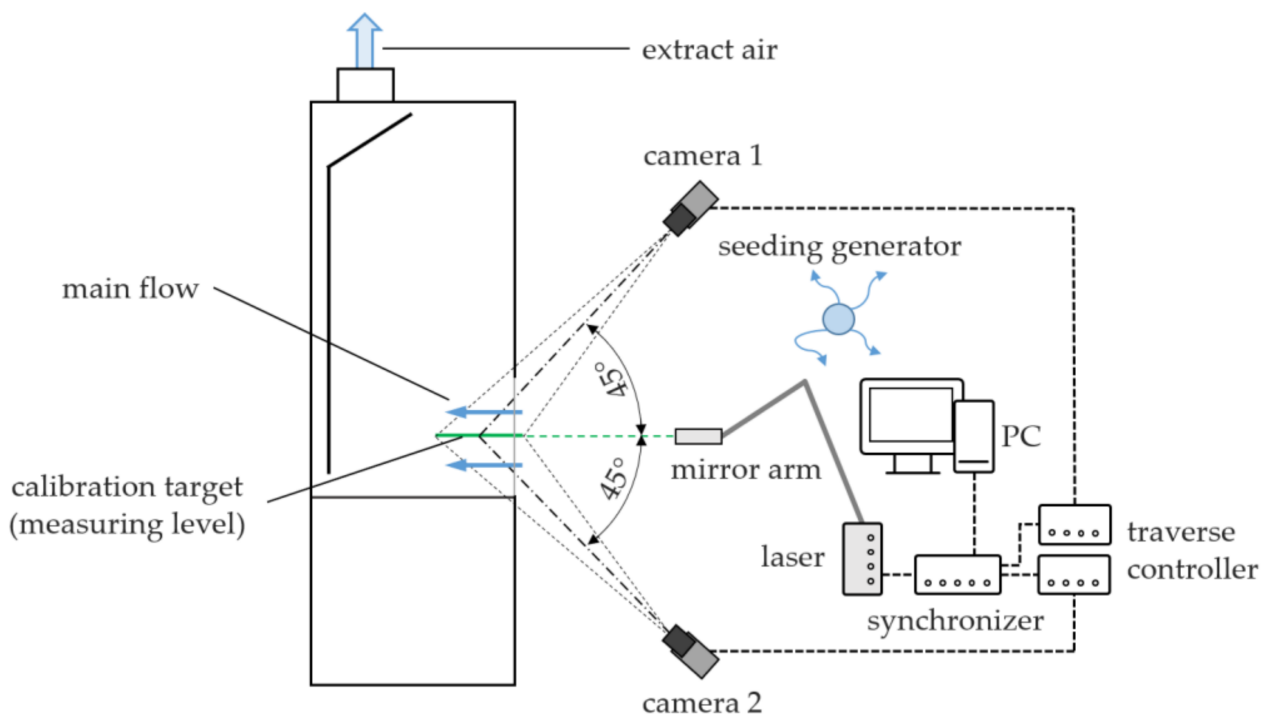

Figure 16. Experimental setup for Stereo PIV measurements on the side post and the subsequent side wall-schematic representation.

A Nd:YAG laser with integrated cooling (Quantel, Twins BSL 200 Q-Switched Multipulse Laser) was used to illuminate the measurement plane and generate the light sheet in conjunction with a 2-m long, slim optical device (ILA, Articulated Mirror Arm) that can be moved in all axes via a multiple joint. This arrangement ensures the least possible disturbance of the flow in front of the measurement plane.

Two identical Charged Coupled Device (CCD) digital cameras (PCO, pco. 2000, 14 bit, $2048 \times 2048$ pixels) with a 50-mm focal length lens and an aperture factor of 1:1.4 (Canon Lens EF 50) were used for image acquisition. The cameras are mounted on a traverse system (ILA, Remote Tilt Camera Mount) and can be positioned with the ILA, Traverse Controller 19". The adjustment of the lenses is done with an ILA Lens Controller, the control of the laser and the cameras with an ILA Synchronizer 2011, 19".

The ILA Multilevel Calibration Target was used to align the image sections and the exact camera settings, see Figure 17.

As described in Section 2.1, it can be assumed that the individual jets merge into one common jet a short distance after their exit. Since the focus of the investigations carried out here is on the effect of the wall jets on the overall flow in the fume hood, the measuring plane was not placed in a nozzle exit opening, but (approximately halfway up the front opening) in the middle of the bridge between two nozzle openings.

The laser was operated at a pulsed frequency of $2 \mathrm{~Hz}$. For each measurement, 500 double images were recorded with both cameras.

The control of the measurement components as well as the evaluation of the measurement data was done with the help of the ILA VidPIV Interface and the ILA PIVView Evaluation Software.

A seeding generator (Palas, AGF. 10.0) adds stable droplet aerosols (Di-Ethyl-HexylSebacat) to the environment.

\subsection{Containment Test According EN 14175-3}

The effects of the above proposed measures to improve the effect of wall jets on the containment capability of the fume hood will be investigated using the test method 
standardized according to EN 14175-3 [38]. This test method, which is established in Europe (as is the ANSI/ ASHRAE Standard 110-2016 [17] used in the USA), is based on the basic principle of a measurement method proposed by Caplan and Knudson [39]: The testing of the containment capability with respect to gaseous emissions occurring in the fume hood. For this purpose, a tracer gas is released inside the fume hood and, at the same time, the concentration of the tracer gas in front of the front opening of the fume hood is measured. With the aid of this test, the safety and energy efficiency of the fume hood can be assessed quantitatively; therefore, among other things, it serves the licensing and health authorities as a basis for determining the maximum permissible concentration in front of the front opening of the fume hood for practical laboratory operation.

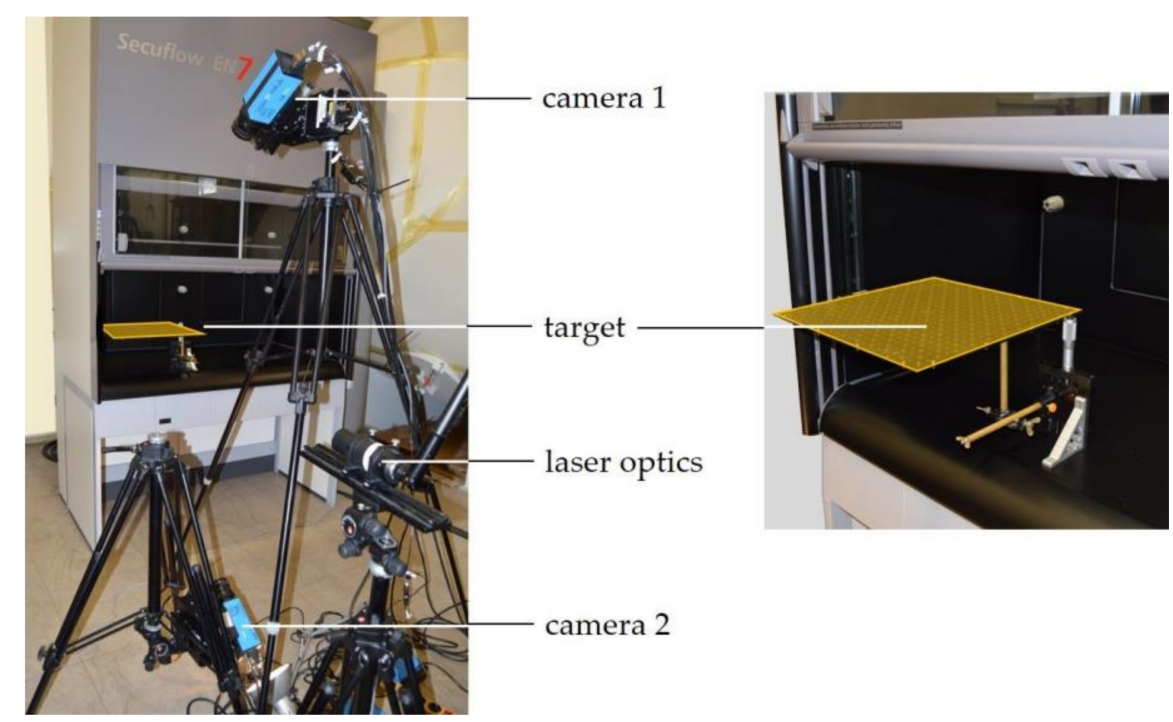

Figure 17. PIV measurements on the laboratory fume hood-photograph of the experimental setup.

The following applies to the test conditions and the test procedure: According to the specifications of the standard, the test room is enclosed on all sides and cuboid-shaped, and it is larger than the minimum specified dimensions. The ambient air temperature in the test room was $23 \pm 3{ }^{\circ} \mathrm{C}$. Temperature gradients in the test room were avoided as far as possible. The temperature of the room supply air to be supplied at a distance of more than $2 \mathrm{~m}$ from the front of the fume cupboard were room air temperature $\pm 1^{\circ} \mathrm{C}$ during measurements.

The test area is defined at the front of the fume hood with a distance of about $1.5 \mathrm{~m}$ to the fume hood and about $1.0 \mathrm{~m}$ to the outer side walls of the fume hood, running from the floor to the test room ceiling. There were no obstacles in the test area or in the fume hood that could interfere with the flow, except for the equipment required for the measurements. During the measurements, no persons were present in the test area and no persons were present in the test room who are not involved in the performance of the test.

The test gas released during the measurement in the interior of the fume hood is composed of $(10 \pm 1) \%$ by volume of the tracer gas sulfur hexafluoride $\left(\mathrm{SF}_{6}\right)$ and $90 \%$ nitrogen $\left(\mathrm{N}_{2}\right)$. The test gas flow rate $(4.5 \mathrm{~L} / \mathrm{min})$ was set using a two-channel mass flow controller (Brooks, type $8576 \mathrm{E}$ ). In order to emit the test gas flow in the interior of the fume hood with as little impulse as possible, a cylindrical silencer for compressed air applications (Festo, type UC-1/8) was used for each of the test gas inlets, which ensures uniform gas discharge due to its fine-pored surface structure.

The total of 30 sampling probes were arranged at grid points resulting from an overlap of vertical and horizontal lines on the outer measuring plane with a limit deviation of $\pm 5 \mathrm{~mm}$ as described in the standard. The samplers were connected by flexible hoses of equal length to a cylindrical sample manifold connected to the gas analyzer. 
An infrared (IR) gas analyzer (MIRAN 1A) was used to measure the gas concentration before the fume hood. This is a single-beam spectrophotometer with a variable filter for setting the infrared range (here to the characteristic wavelength for $\mathrm{SF}_{6} 10.65 \mu \mathrm{m}$ ) and a long-path gas cell with a volume of 5.6 1 . The intensity of the monochromatic light beam deflected several times in the gas cuvette is measured by a photomultiplier. The measured infrared absorption can be used to determine the $\mathrm{SF}_{6}$ concentration in the air flow continuously pumped through the gas cuvette. The experimental setup for the containment test is shown in schematically in Figure 18.

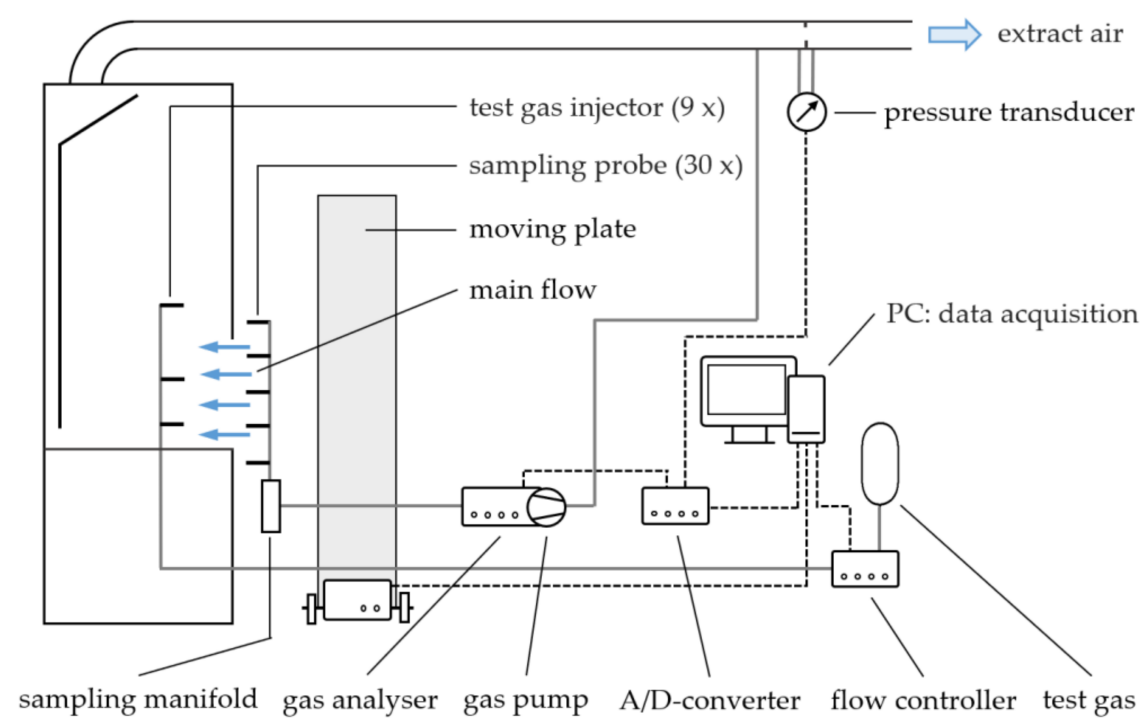

Figure 18. Experimental setup for the test of the robustness of containment according to EN 141753 [38], schematic representation.

A flat rectangular plate with a height of $1900 \mathrm{~mm}$ and a width of $400 \mathrm{~mm}$ was set up in front of the fume hood, see Figure 19. During the test, the plate moved at a speed of $1 \pm 0.1 \mathrm{~m} / \mathrm{s}$ at a distance of $400 \pm 05 \mathrm{~mm}$ across the front of the fume hood. The movement path of the plate extended $600 \mathrm{~mm}$ beyond the outer width of the fume hood on each side. The time between each traverse was $30 \pm 2 \mathrm{~s}$. To allow for stabilization, the movement of the plate started $60 \mathrm{~s}$ after the test gas $(4.5 \mathrm{~L} / \mathrm{min})$ was switched on and ended after six complete traverses. The gas analyzer signal is recorded for an additional $60 \mathrm{~s}$. Each test was repeated two more times under the same test conditions.

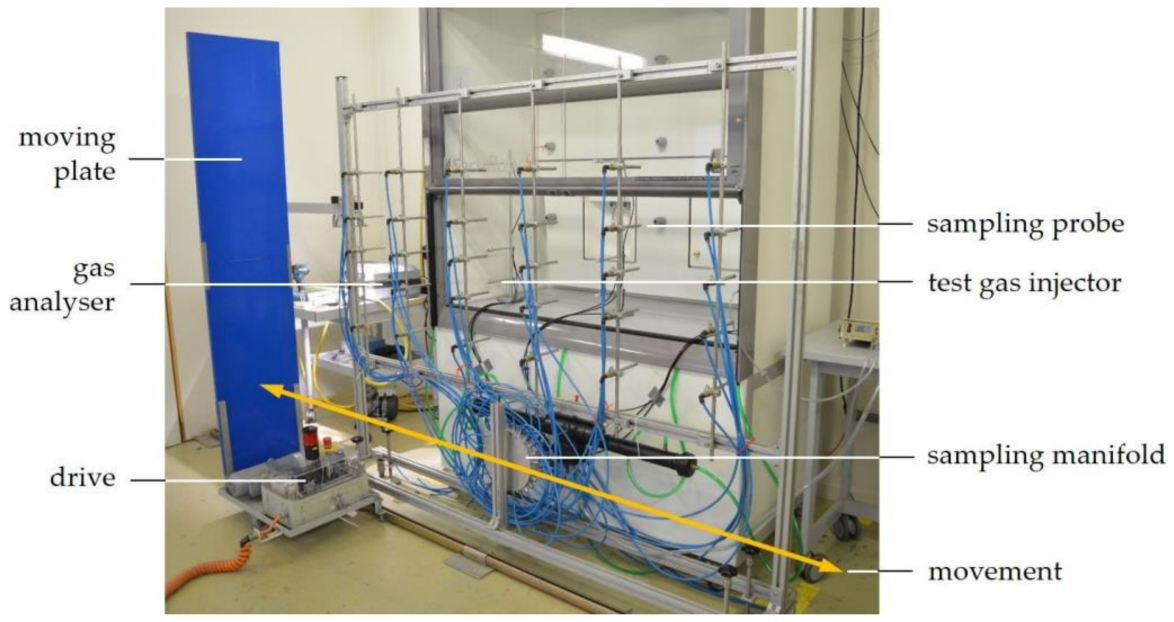

Figure 19. Moving plate for testing robustness of containment according to EN 14175-3 [38]. 
An amplifier combined with an analog/digital converter (Keithley, Data Acquisition Module KUSB-3108, 16-bit, $50 \mathrm{kHz}$ ) and a PC with the LabVIEW program were used to record the measured values and to control the flow controller for the tracer gas as well as the drive for the moving plate, which was also used to evaluate the measured data.

According to the standard, the exhaust air volume flow set for the tests must be measured in the exhaust air duct to which the fume hood is connected in accordance with ISO 5167-1 [40]. The measurement uncertainty was $\pm 4 \%$, thus complying with the required $\pm 5 \%$.

\section{Results and Discussion}

\subsection{Flow Visualization}

Visualization of the inlet flow in the area of the side posts bounding the front opening and the subsequent side walls was carried out using the smoke wire device described in Section 4.1. The experimental setup allowed for observation of the air entering the inner space of the fume hood from the ambient environment through the front opening, special attention being paid to assessing the effect of the wall jets in the various nozzle designs investigated.

As suggested by the numerical simulations, the flow separates downstream of the leading edge in the laboratory fume hood with no wall jets, see Figure 20a. The strong recirculation zone displaces the incoming flow even at a further distance from the side posts. Using the steady wall jet even in the baseline fume hood improves the situation significantly, the separation region is smaller as well as the flow displacement, see Figure 20b.

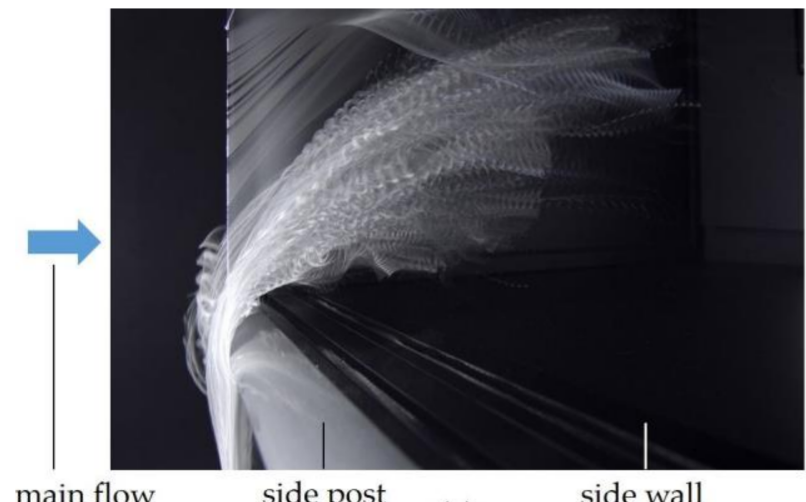

main flow side post

(a)

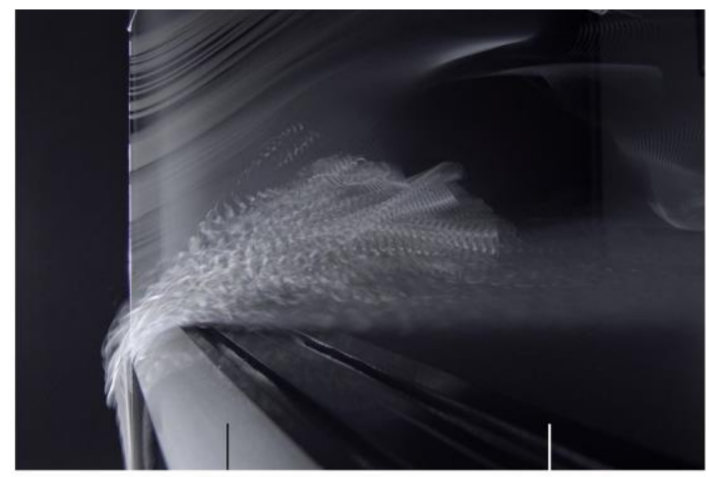

(b) side wall

Figure 20. Streaklines in the area of side post and side wall: (a) Conventional fume hood with no flow control; (b) Baseline fume hood with wall jets, $\dot{S}=48 \mathrm{~m}^{3} / \mathrm{h}, C_{\mu}=2.25$.

The recirculation area with its turbulent flow structures, which in the investigated baseline fume hood already formed at the leading edge of the side post profile and widened in the direction of flow (Figure 20b), were no longer visible in either the improved version with steady blowing jets or the version with oscillating jets. The flow deflected at the leading edge follows the contour of the side post. The main flow no longer moves away from the side wall; on the contrary, the wall jets draw ambient air from the main flow so that it is even deflected toward the side wall. The wall jet blowing out at the end of the curved profile section lies flat against the side wall and widens less visibly with increasing distance than in the series design, see Figure 21.

Visualization of the discharge angle and mixing of the jet with the ambient was carried out using the fog generator integrated into the distribution housing of the jet air supply described in Section 4.1. In the baseline, the jets rise after exiting the side post profile at an angle of approximately $30^{\circ}$ to the horizontal (Figure 22a), while in the improved nozzle design they run horizontally (parallel to the worktop) to the rear, see Figure 22b. This 
improvement can be attributed to the guide ratio $F$ in the nozzle channel being increased from 0.5 to 9 .

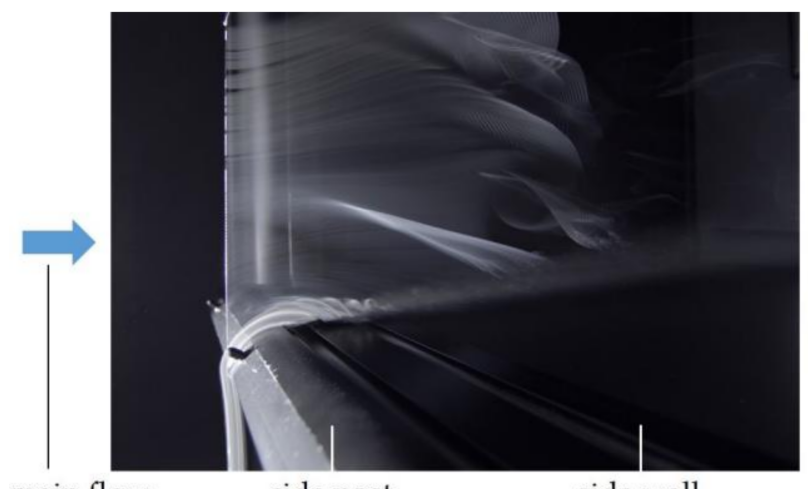

main flow side post

(a)

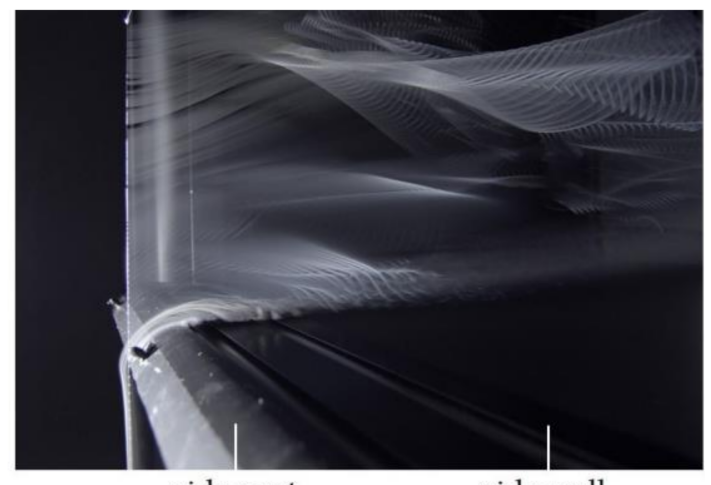

(b)

Figure 21. Streaklines in the area of side post and side wall: (a) fume hood with improved jet nozzles, steady outflow, $\dot{S}=14.1 \mathrm{~m}^{3} / \mathrm{h}, \dot{I}=3.6 \times 10^{-4} \mathrm{~kg} \cdot \mathrm{m} / \mathrm{s}^{2}$ and (b) fume hood with oscillators, $\dot{S}=6.8 \mathrm{~m}^{3} / \mathrm{h}, C_{\mu}=1.78$.

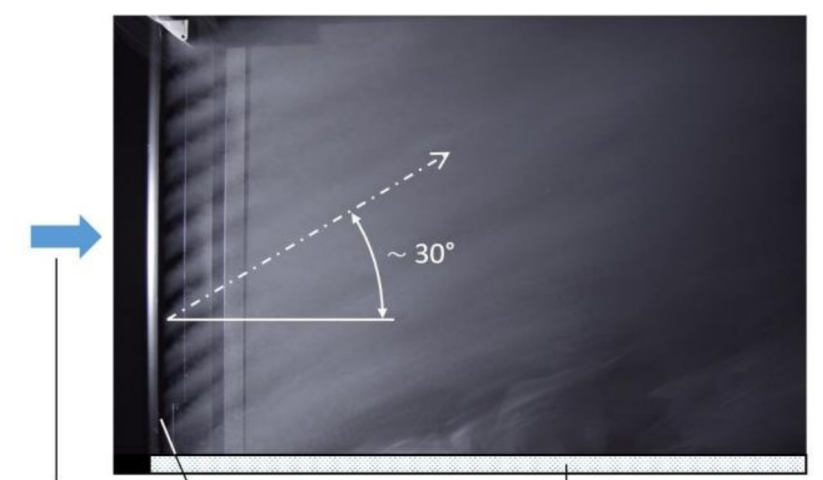

main flow side post (a) worktop

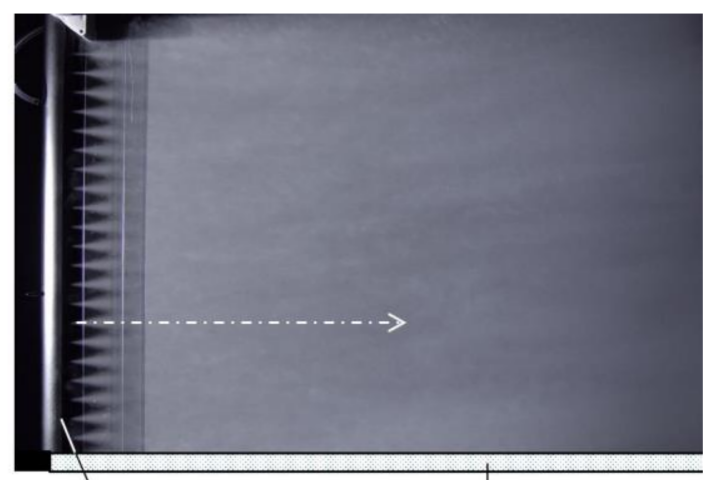

(b) worktop

Figure 22. Jet direction: (a) baseline directed obliquely upwards and (b) improved nozzle design with horizontal orientation.

Lowering the jet exit velocity from $c_{0}=10 \mathrm{~m} / \mathrm{s}$ (velocity for which the oscillators were designed) to $c_{0}=5 \mathrm{~m} / \mathrm{s}$ showed a different picture of the individual jets directly after their exit, see Figure 23a. Two areas can be distinguished: in the first area, a thin jet with a uniform width can be observed, which begins to spread out in the second area, starting at a distance of about 10 to $25 \mathrm{~mm}$ after exit. The angle of propagation and mixing with the environment differ significantly from one jet to the other. The uniform, directional start of the jet indicates that no oscillation is taking place at this jet exit velocity. It is reasonable to assume that the different jet propagation in the second part is caused by geometry deviations of the nozzles produced in the 3D printing process (manufacturing tolerances or residues in the nozzle inner space). If the jet exit velocity is increased to $10 \mathrm{~m} / \mathrm{s}$ (design velocity), turbulent mixing with the ambient air begins immediately after the jet exit. The individual jets differ only slightly in shape from one another and they quickly merge to form an overall jet, see Figure $23 \mathrm{~b}$. As expected, the propagation angle is larger for oscillating jets than for steady jets due to the oscillating motion, compare Figure 23b with Figure 22b.

If the momentum coefficient is assumed to be $100 \%$ for the baseline, it is $79 \%$ of the initial value for the improved nozzles with steady outflow and only $40 \%$ for the oscillators. Despite the lower momentum coefficient, the intended effect, namely the prevention of flow separation and recirculation, is more effective for both proposed designs than for the baseline. 


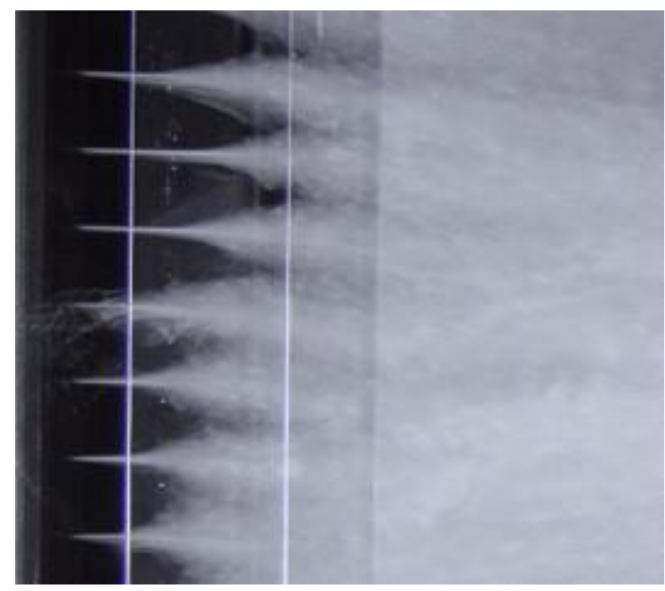

(a)

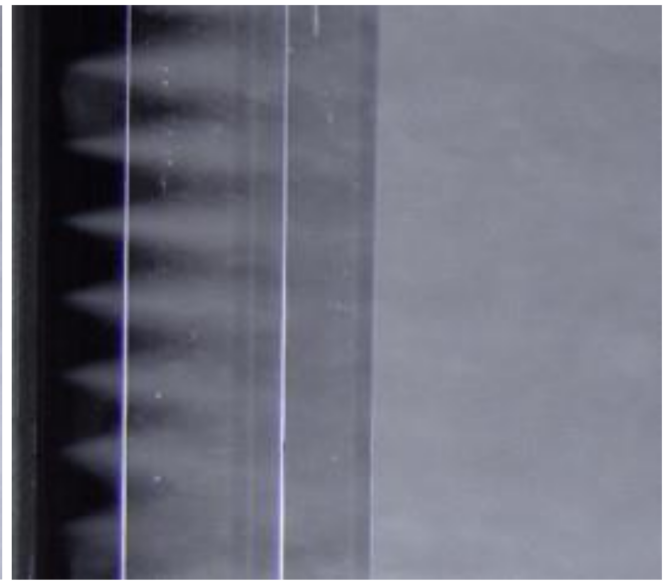

(b)

Figure 23. Oscillating jets: (a) jet exit velocity $c_{0}=5 \mathrm{~m} / \mathrm{s}$ and (b) jet exit velocity $c_{0}=10 \mathrm{~m} / \mathrm{s}$.

In the case of the improved nozzle design with steady outflow, this can be attributed to the reduced jet exit angle to the wall from $\beta=25^{\circ}$ to $\beta=5^{\circ}$ and the increased guide ratio of the nozzle channel from $F=0.5$ to $F=9$. The fact that the comparable effect is achieved with the oscillators with a significantly smaller momentum coefficient is due to the better mixing properties of the oscillating jet and thus the more intensive energy input into the boundary layer.

\subsection{Particle Image Velocimetry (PIV)}

The aim of the experimental setup for the PIV measurements described in Section 4.2 is to assess the effects of controlling the flow in the fume hood and, in particular, the improved effect of the proposed new nozzle designs. The method of the stereo PIV measurements used here makes it possible to spatially record the velocities in the flow field under investigation.

The magnitude of the velocities $|u|$ shown in the diagrams in Figure 24 is composed of the individual velocities measured in all three axes and is normalized by the mean face velocity $\bar{u}_{r e f}$ :

$$
|u|=\frac{\sqrt{\bar{u}^{2}+\bar{v}^{2}+\bar{w}^{2}}}{\bar{u}_{r e f}}
$$

where $\bar{u}$ is the mean velocity in X-direction, $\bar{v}$ is the mean velocity in Y-direction, and $\bar{w}$ is the mean velocity in Z-direction.

The inlet flow deflected in the front opening in the fume hood without flow control already detaches at the leading edge of the side post and forms an oval recirculation area with low velocities in the subsequent area of the side wall. The recirculation area extends to about $200 \mathrm{~mm}$ behind the leading edge, after which the streamlines run parallel to the wall, see Figure 24a. The fluid mechanical causes leading to this picture, which is characteristic for conventional fume hoods with no flow control, are described in Section 2.1.

Although the wall jets in the baseline fume hood cannot prevent the separation after the leading edge of the side profile, the recirculation area observed without flow control (Figure 24a) is greatly reduced, see Figure 24b.

Furthermore, it can be seen in Figure 24b that the streamlines in the horizontal measuring plane move away from the sidewall at an angle of up to $45^{\circ}$ from a distance of about $150 \mathrm{~mm}$ behind the leading edge. The direction of the streamlines and the threedimensional velocity contours, which show significantly increased amounts in this area, show that the jets blown in in the baseline are only partially in contact with the wall and are therefore not true wall jets. 


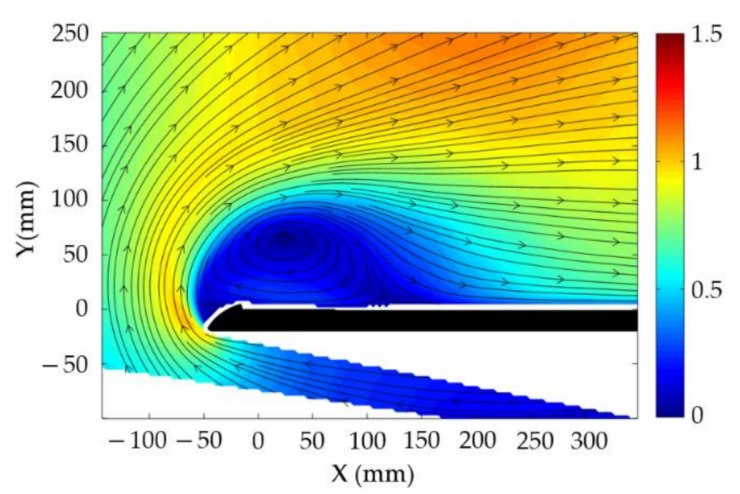

(a)

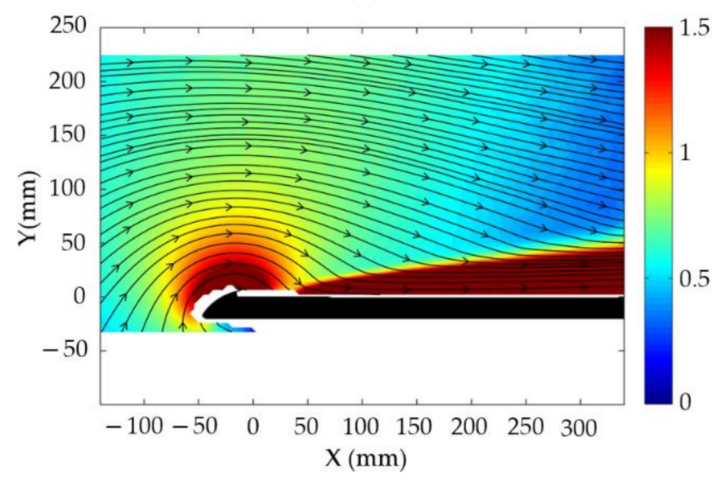

(c)

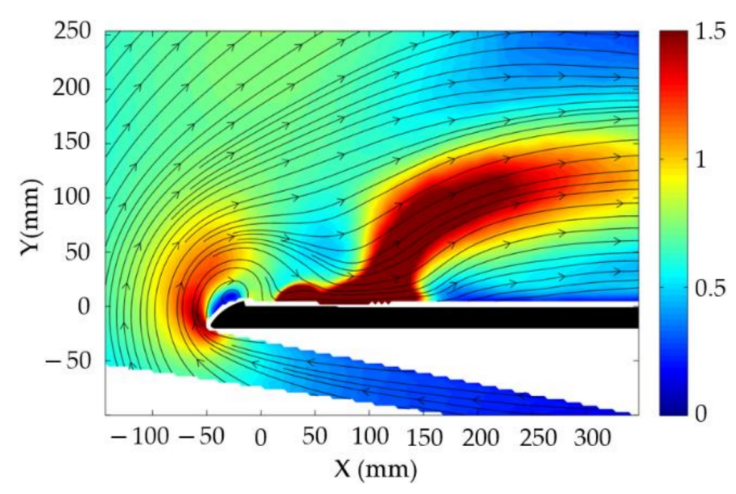

(b)

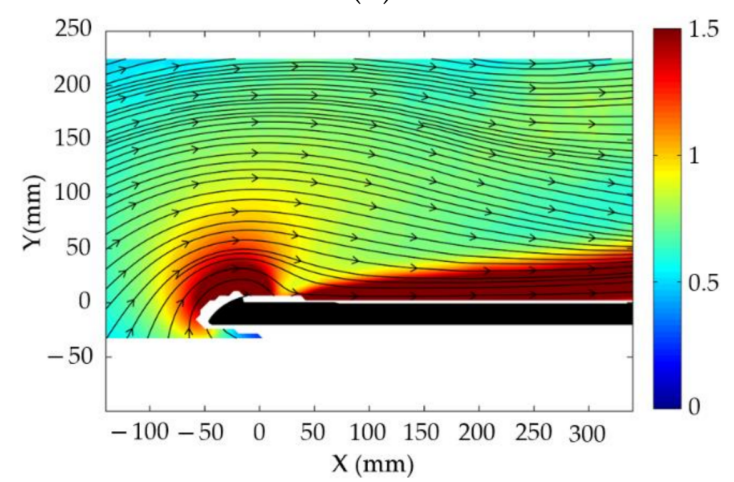

(d)

Figure 24. Flow in the area of side post and side wall. Diagrams with sectional streamlines of the mean flow field in the measuring level and contours of the three-dimensional velocity magnitude normalized by the mean inflow velocity: (a) fume hood with no flow control; (b) baseline fume hood, $\dot{S}=48 \mathrm{~m}^{3} / \mathrm{h}, C_{\mu}=2.25$; (c) fume hood with improved nozzles, $\dot{S}=14.1 \mathrm{~m}^{3} / \mathrm{h}, C_{\mu}=1.78$; and (d) fume hood with oscillators, $\dot{S}=6.8 \mathrm{~m}^{3} / \mathrm{h}, C_{\mu}=0.89$.

The wall jets in the fume hood with improved nozzles with steady outflow as well as with oscillators completely prevent separation and recirculation after the leading edge. The initially curved streamlines in Figure $24 c, d$ run parallel to the wall in the entire measurement field already after about $80 \mathrm{~mm}$ after the leading edge, and the magnitude of the velocity near the wall is significantly increased compared to the main flow.

Even though the diagrams in Figure $24 \mathrm{c}$,d look very similar at first view, it must be noted when evaluating the two designs that the effect shown is achieved with the oscillating jets with a $60 \%$ lower momentum coefficient than the baseline. The fact that the comparable effect is achieved with the oscillators with a significantly smaller momentum coefficient is due to the better mixing properties of the oscillating jet and, thus, the more intensive energy input into the boundary layer.

Since the base flow and reference area are assumed to be the same in the three cases investigated, the momentum coefficient is also (in simplified terms) a measure of the energy required to generate the jet. From this follows that the oscillators are clearly superior to the two designs with steady outflow.

Experimental investigations on the baseline fume hood, in which the jet flow was made visible, showed that the jets do not run horizontally backwards after their exit in the inner space, but are directed obliquely upwards at an angle of about $30^{\circ}$ to the horizontal (Figure 22a). This qualitative observation is confirmed by the PIV measurements.

In the conventional fume hood without flow control, the flow in the inner space of the fume hood is horizontal in the PIV measurement field, and no velocity component $\bar{w}$ was measured normal to the horizontal measuring level, see Figure 25a.

In contrast, a vertical velocity was detected in the fume hood with wall jets in the baseline design. After the jet exit, an upward velocity component occurs downstream, with 
the range extending to about $100 \mathrm{~mm}$ from the side wall. At a greater distance from the wall, this upward motion (caused by the obliquely upward wall jets) causes a downward compensating flow, which occurs upstream in the wall region and extends from the leading edge of the side post profile to the jet exit.

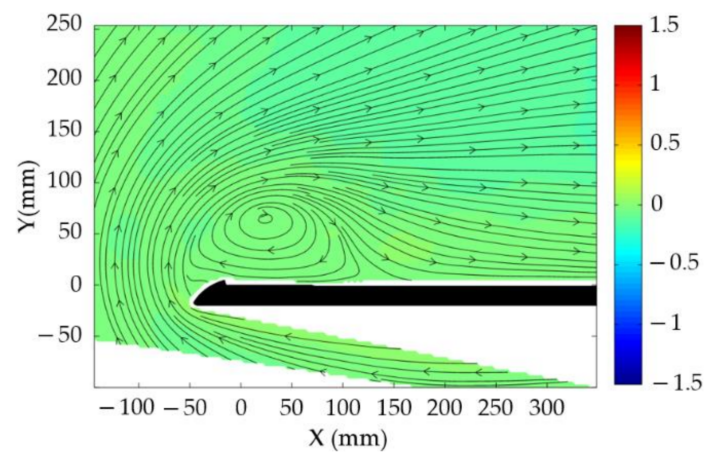

(a)

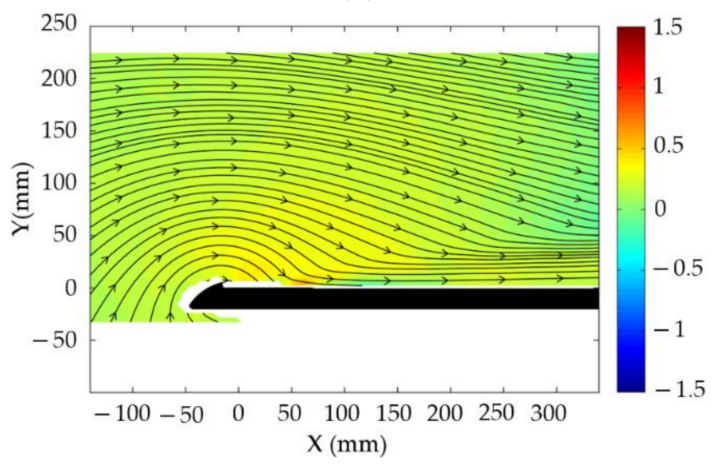

(c)

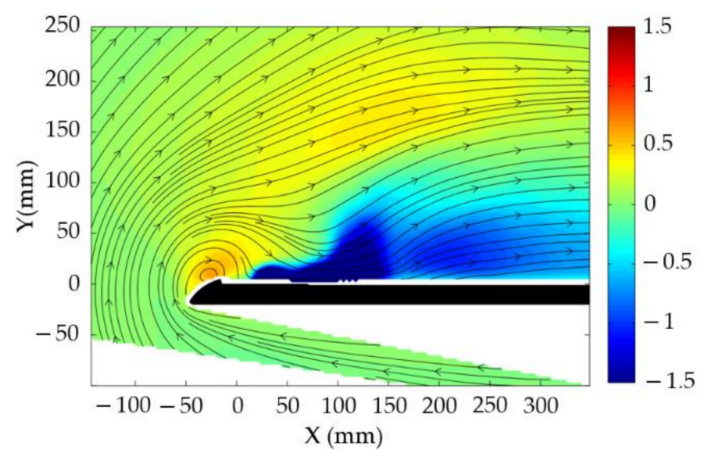

(b)

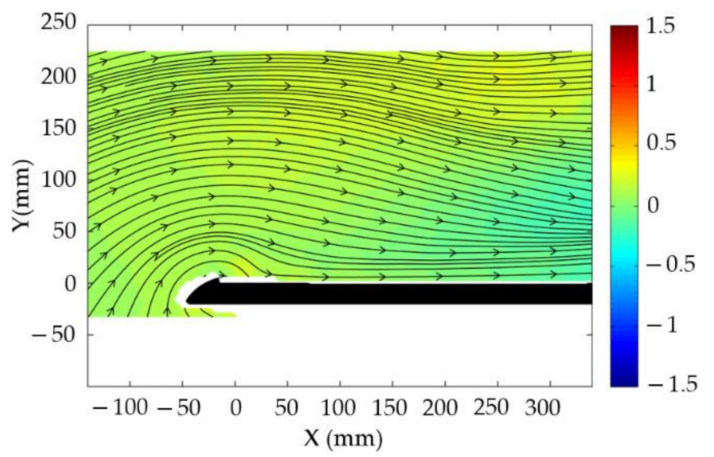

(d)

Figure 25. Flow in the area of side post and side wall. Diagrams with sectional streamlines of the mean flow field in the horizontal measuring level and contours of the velocity magnitude in Z-direction normalized by the mean inflow velocity: (a) fume hood with no flow control; (b) baseline fume hood, $\dot{S}=48 \mathrm{~m}^{3} / \mathrm{h}, C_{\mu}=2.25$; (c) fume hood with improved nozzles (steady outflow), $\dot{S}=14.1 \mathrm{~m}^{3} / \mathrm{h}, C_{\mu}=1.78$; and (d) Fume hood with oscillators, $\dot{S}=6.8 \mathrm{~m}^{3} / \mathrm{h}, C_{\mu}=0.89$.

For the improved nozzle design with steady outflow, only a very small vertical (upward) velocity component was measured compared to the baseline design, see Figure 25c. A downward compensating flow could no longer be detected. In the design with oscillators, no significant vertical velocity components were measured in the entire measurement field, see Figure 25d. This shows that with both suggested nozzle designs (steady and oscillating outflow), the jets flow horizontally after discharge, parallel to the worktop, directly toward the suction openings in the back wall. This supports the secondary effect described in Section 2.1, which is to be achieved with the help of the wall jets in addition to the prevention of flow separation and recirculation: Improvement of the transport away of gaseous or particulate substances being released in the inner space and coming to the wall area.

\subsection{Containment Test According EN 14175-3}

The tests carried out here are intended to determine the minimum extract air flow rate for the fume hood equipped with the different nozzle designs at which the maximum permissible tracer gas values according to BG Fachausschuss Chemie [41] are not exceeded. EN 14175-3 [38] describes different possibilities for testing the containment capability of the fume hood. These are, on the one hand, static measurements without disturbances from the environment and, on the other hand, dynamic testing of the robustness of the containment. The evaluation of measurement data from static and dynamic tests of previously performed tests on more than 30 different designs of fume hoods has shown that the minimum exhaust 
air volume flow is determined without exception by the results of the test of the robustness of containment, since the challenge to the containment capability of the fume hood is obviously less in the static tests than in the dynamic robustness of containment test with the moving plate in front of the fume hood. For this reason, the tests described below focus on the robustness of containment-static tests were not performed for the above reasons. To determine the required minimum extract air volume flow rate, the extract air volume flow rate was reduced to $310 \mathrm{~m}^{3} / \mathrm{h}$ in steps of $10 \mathrm{~m}^{3} / \mathrm{h}$ for the test of the robustness of containment, starting at $440 \mathrm{~m}^{3} / \mathrm{h}$. For each extract air flow rate set, the test was repeated and recorded three times (in immediate succession). To present the measurement results, the arithmetic mean of the measured tracer gas concentration is formed from the mean values of the triple tests.

The results of the tests show that the minimum extract air flow rate of the fume hood with the improved nozzles with steady blowing jets is $12 \%$ lower than in the baseline. For the fume hood with the fluidic oscillators, the minimum extract air flow rate is $22 \%$ lower than in the baseline. These values were determined from the intersections of the trend lines with the limit line, see Figure 26.

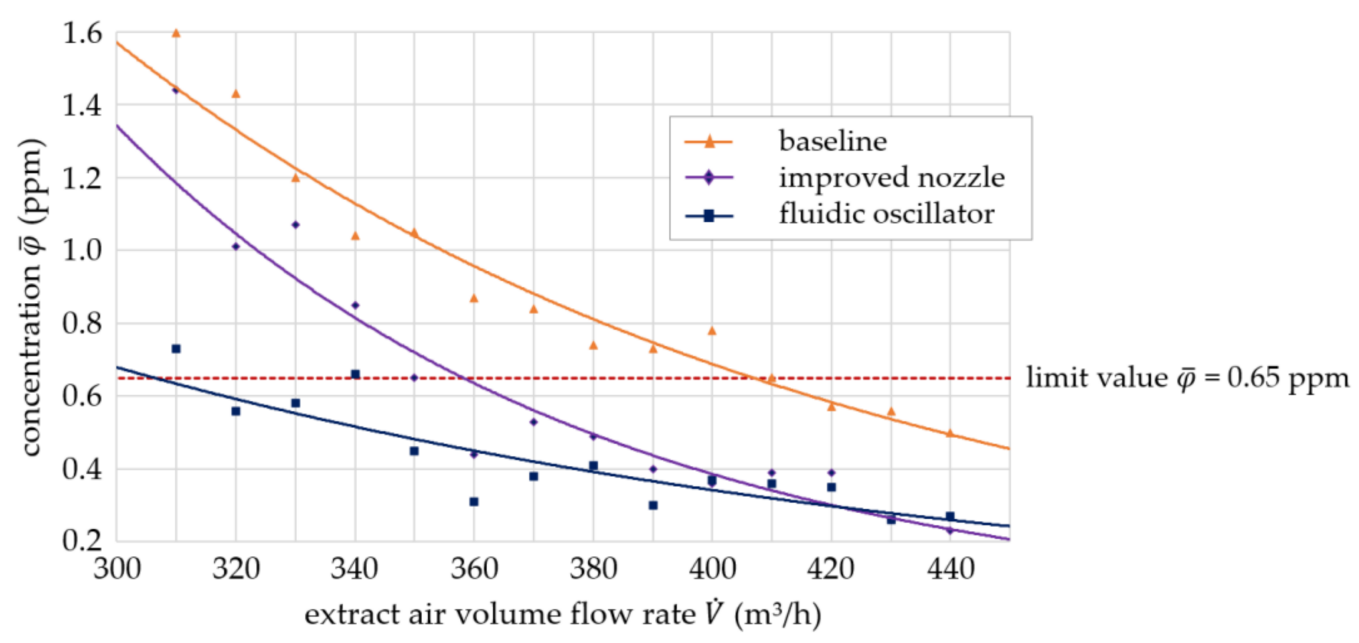

Figure 26. Mean tracer gas concentration $\bar{\varphi}$ as a function of extract air flow rate $\dot{V}$ in different nozzle designs.

The resulting minimum extract air flow rates at which the measured tracer gas concentrations are below the specified limits are:

- Baseline $\dot{V}=410 \mathrm{~m}^{3} / \mathrm{h}$.

- Improved nozzle $\dot{V}=360 \mathrm{~m}^{3} / \mathrm{h}$.

- Fluidic oscillator $\dot{V}=320 \mathrm{~m}^{3} / \mathrm{h}$.

Evaluation of the tests conducted at a constant extract air flow rate of $320 \mathrm{~m}^{3} / \mathrm{h}$ reveals a characteristic pattern that has already been observed in previous tests of the robustness of containment of fume hoods of different models: The plate moving transversely in front of the fume hood creates an unstable inflow as it passes the front opening of the fume hood, resulting in a briefly increasing and then decreasing tracer gas concentration in the measurement plane, see Figure 27.

For the specified limit values, a distinction is made between the maximum permissible mean value of $\bar{\varphi}=0.65 \mathrm{ppm}$ and the maximum permissible peak value of $\varphi_{\max }=3.25 \mathrm{ppm}$ $\left(\varphi_{\max }=5 \cdot \bar{\varphi}\right)$. It shows for all measured configurations that the minimum extract air flow rate is not determined by the maximum permissible value $\varphi_{\max }$, but by the maximum permissible average value $\bar{\varphi}$, see Figure 27. 


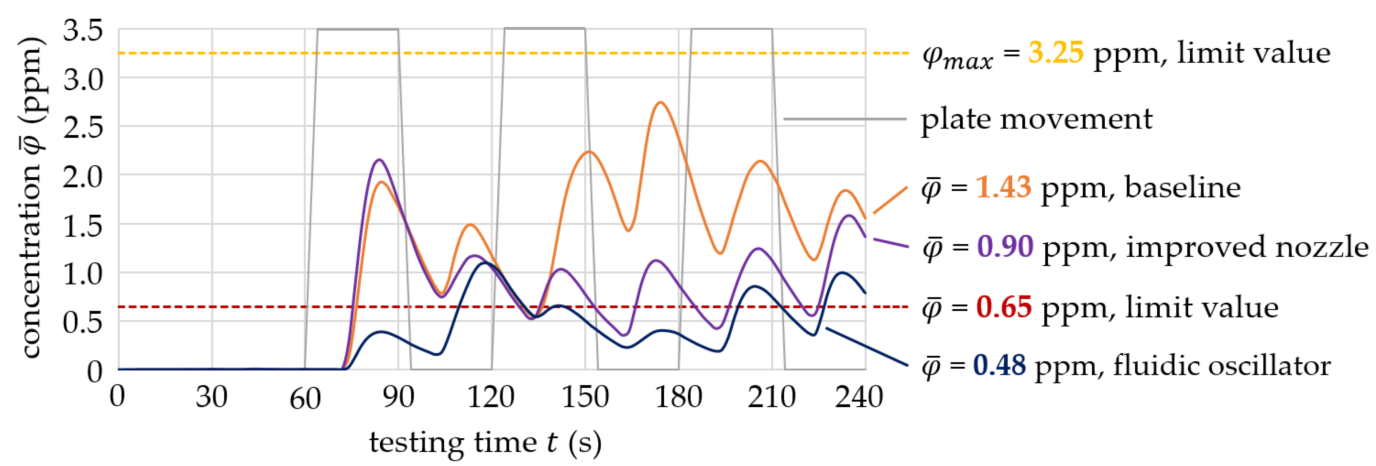

Figure 27. Robustness of containment at an extract volume flow rate of $320 \mathrm{~m}^{3} / \mathrm{h}$. Fume hood with different nozzle designs.

\section{Conclusions}

Within the framework of the investigations presented here, it was shown that the minimum extract air volume flow rate required for safe operation of a laboratory fume hood can be reduced by controlling the flow with the aid of self-excited oscillating wall jets. The minimum extract air volume flow rate, which can be equated in a first approximation with the energy requirement for operating the laboratory fume hood, is reduced by $22 \%$ compared to the baseline by using the oscillators.

The tests of the fume hood's containment capability have shown that the effects observed in the area of impact of the wall jets-above all prevention of flow separation and recirculation - have a positive effect on the containment capability, thus improving the safety of the fume hood while at the same time lowering the required minimum extract air volume flow rate.

The better mixing properties of the oscillating jet compared to the steady jet lead, on the one hand, to a more intensive energy input into the boundary layer and, on the other hand, due to the vortices directed in the flow direction in the flow field of the jet, a larger area downstream is influenced by the jet. On this basis, it could be shown that the desired effect of the jets with the oscillators is achieved with a significantly smaller momentum coefficient, which leads to a reduction of the jet volume flow to only $14 \%$ of the baseline.

The results of the numerical simulation carried out for the design of the oscillator show a good agreement with the results of the experimental investigations. The qualitative results of the flow visualization agree very well with the quantitative results of the PIV measurements.

Author Contributions: Conceptualization, J.L. and C.O.P.; methodology, J.L. and C.O.P.; validation, J.L. and C.O.P.; formal analysis, C.O.P.; investigation, J.L.; resources, J.L.; data curation, J.L.; writingoriginal draft preparation, J.L.; writing-review and editing, J.L. and C.O.P.; visualization, J.L.; supervision, C.O.P.; project administration, J.L.; funding acquisition, J.L. All authors have read and agreed to the published version of the manuscript.

Funding: This research was funded by WALDNER LABOREINRICHTUNGEN GMBH \& CO. KG.

Acknowledgments: We acknowledge support by the German Research Foundation and the Open Access Publication Fund of TU Berlin.

Conflicts of Interest: The authors declare no conflict of interest. The funders had no role in the design of the study; in the collection, analyses, or interpretation of data; in the writing of the manuscript, or in the decision to publish the results.

\section{References}

1. Ahn, Z. Entwicklung, Bau und Überprüfung von Einrichtungen zur Simulation der Stofffreisetzungs- und Stoffausbreitungsvorgänge in Laboratorien mit Tracergastechnik. Studienarbeit, IKE 7-D-321; Universität Stuttgart: Stuttgart, Germany, 1996.

2. Dittrich, E. (Ed.) Handbuch für Nachhaltige Laboratorien; Erich Schmidt Verlag GmbH \& Co. KG: Berlin, Germany, 2012.

3. Egnaton Cert. Available online: http://www.egnaton.com/de/CERT.aspx (accessed on 4 October 2020). 
4. Sterns, M. Laborabzüge-Ressourcenschonung, Kostenreduktion und Sicherheit. In GIT Labor-Fachzeitschrift; 28 July 2017 ; pp. 22-23.

5. Liebsch, J. Laboratory Fume Hood. European Patent Specification EP 2,419,224B1, 16 April 2010.

6. Smith, C.; Curd, P.; Trinh, T. Airfoil and Baffle Assemblies That Reduce Airflow Requirements for Fume Hoods and Fume Hoods Incorporating Same. U.S. Patent 9,056,339, 27 August 2010.

7. Rindoks, K.; Vaughn, M. Laboratory Hood with Venturi Effect Air Intake Device for Anti-Turbulent Airflow Control. U.S. Patent 10,807,131, 2 November 2017.

8. Liebsch, J. Energiesparende Abzüge—Ein Beitrag zur Nachhaltigkeit; Dechema Kolloqium: Frankfurt, Germany, 2011.

9. Huang, R. Reverse Oblique Air Curtain Exhaust Cabinet. European Patent Specification EP 2,327,484B1, 26 November 2009.

10. Koppenwallner, G. Frontale Absaugverfahren. Available online: http:/ / ploland.de/pdf/froty.pdf (accessed on 28 November 2017).

11. BURDINOLA S.COOP. Safer Labs. Fume Cupboards and Extraction Equipments. Available online: http://burdinola.com/pdf/ technical_catalogue_fume_cupboards.pdf (accessed on 1 June 2018).

12. Gärtner, U.; Liebsch, J. Fume Cupboard. European Patent Specification EP 1,444,057B1, 11 August 2004.

13. Wesemann GmbH. Deltaguard Protect. Available online: https://www.wesemann.com/Produkte/System-DELTA-30 /Abzugssysteme/DE_index_2009_2345.html (accessed on 5 January 2021).

14. Waldner Laboreinrichtungen GmbH \& Co. KG. Secuflow Fume, Cupboards; Waldner Laboreinrichtungen GmbH \& Co. KG.: Wangen, Germany, 2018.

15. Laborbau Systeme Hemling GmbH \& Co. KG. Laborabzüge, Einhausungen und Kabinen. Available online: https://www. hemling.de/katalog/laborbau-2018/book.html\#p=30 (accessed on 12 February 2021).

16. Liebsch, J. Aktive Beeinflussung der Strömung in einem Laborabzug zur Erhöhung der Sicherheit und Energieeffizienz. Ph.D. Thesis, Technische Universität Berlin, Berlin, Germany, 2021.

17. ANSI/ASHRAE Standard 110-2016. In Method of Testing Performance of Laboratory Fume Hoods. American Society of Heating; Refrigerating and Air Conditioning Engineers Inc.: Atlanta, GA, USA, 2016.

18. Oshima, E.K.; Gharib, M.; Reichert, R.; Wygnanski, I.J. On Parameters Defining Active Flow Control. In Proceedings of the 2021 AIAA AVIATION Forum, virtual, 2-6 August 2021.

19. Rietschel, H.; Esdorn, H. Raumklimatechnik Band 1: Grundlagen. Lehrbuch; Springer Verlag: Berlin Heidelberg, Germany, 2008.

20. Nasr, A.; Lai, J. The Effects of Wall Inclination on an Inclined Offset Jet; Iran University of Science \& Technology: Teheran, Iran; The University of New South Wales: Canberra, Australia, 2000.

21. Waldner Laboreinrichtungen GmbH \& Co. KG. Scala Laboratory System, Technical Catalogue; Waldner Laboreinrichtungen GmbH \& Co. KG.: Wangen, Germany, 2019.

22. Goodfellow, S.D.; Yarusevych, S.; Sullivan, P. Momentum Coefficient as a Parameter for Aerodynamic Flow Control with Synthetic Jets. AIAA J. 2013, 51, 623-631. [CrossRef]

23. Guyot, D.; Bobusch, B.; Paschereit, C.O.; Raghu, S. Active Combustion Control Using a Fluidic Oscillator for Asymmetric Fuel Flow Modulation. In Proceedings of the 44th AIAA/ASME/SAE/ASEE Joint Propulsion Conference \& Exhibit, Hartford, CT, USA, 21-23 July 2008.

24. Lacarelle, A. Modeling, Control and Optimization of Fuel/Air Mixing in a Lean Premixed Swirl Combustor Using Fuel Staging to Reduce Pressure Pulsations and NOx Emissions. Ph.D. Thesis, Technische Universität Berlin, Berlin, Germany, 2011.

25. Lacarelle, A.; Paschereit, C.O. Increasing the Passive Scalar Mixing Quality of Jets in Crossflow with Fluidics Actuators. J. Eng. Gas Turbines Power 2011, 134, 021503. [CrossRef]

26. Seele, R.; Tewes, P.; Woszidlo, R.; McVeigh, M.A.; Lucas, N.J.; Wygnanski, I.J. Discrete Sweeping Jets as Tools for Improving the Performance of the V-22. J. Aircr. 2009, 46, 2098-2106. [CrossRef]

27. Cerretelli, C.; Kirtley, K. Boundary layer separation control with fluidic oscillators. J. Turbomach. 2009, 131, 1-9. [CrossRef]

28. Culley, D.E.; Bright, M.M.; Prahst, P.S.; Strazisar, A.J. Active Flow Separation Control of a Stator Vane Using Surface Injection in a Multistage Compressor Experiment. J. Turbomach. 2003, 126, 24-34. [CrossRef]

29. Seifert, A.; Stalnov, O.; Sperber, D.; Arwatz, G.; Palei, V.; David, S.; Dayan, I.; Fono, I. Large Trucks Drag Reduction Using Active Flow Control. In The Aerodynamics of Heavy Vehicles II: Trucks, Buses, and Trains; Springer: Berlin/Heidelberg, Germany, 2008. [CrossRef]

30. Raman, G.; Raghu, S. Cavity Resonance Suppression Using Miniature Fluidic Oscillators. AIAA J. 2004, 42, 2608-2612. [CrossRef]

31. Ostermann, F.; Woszidlo, R.; Nayeri, C.N.; Paschereit, C.O. Properties of a sweeping jet emitted from a fluidic oscillator. J. Fluid Mech. 2018, 857, 216-238. [CrossRef]

32. Gregory, J.; Tomac, M. A Review of Fluidic Oscillator Development and Application for Flow Control. In Proceedings of the 43rd AIAA Fluid Dynamics Conference 2013, San Diego, CA, USA, 24-27 June 2013.

33. Bobusch, B.C.; Woszidlo, R.; Bergada, J.M.; Nayeri, C.; Paschereit, C.O. Experimental study of the internal flow structures inside a fluidic oscillator. Exp. Fluids 2013, 54, 1-12. [CrossRef]

34. Ostermann, F. Fundamental Properties of a Spatially Oscillating Jet Emitted by a Fluidic Oscillator. Ph.D. Thesis, Technische Universität Berlin, Berlin, Germany, 2018.

35. Menter, F.R. Two-equation eddy-viscosity turbulence models for engineering applications. AIAA J. 1994, 32, 1598-1605. [CrossRef]

36. Krüger, O.; Bobusch., B.C.; Woszidlo, R.; Paschereit, C.O. Numerical Modeling and Validation of the Flow in a Fluidic Oscillator. In Proceedings of the 21st AIAA Computational Fluid Dynamics Conference, San Diego, CA, USA, $24-27$ June 2013. 
37. Dol, S.S.; Nor, M.A.; Kamaruzaman, M.K. An Improved Smoke-Wire Flow Visualization Technique. In Proceedings of the 4th WSEAS International Conference on Fluid Mechanics and Aerodynamics, Elounda, Greece, 21-23 August 2006.

38. EN 14175-3:2019. Fume Cupboards, Part 3: Type Test Methods; German Version: DIN EN 14175-3:2019; Beuth Verlag GmbH: Berlin, Germany, 2019.

39. Caplan, K.J.; Knudson, G.W. Laboratory fume hoods: A performance test. ASHRAE Trans. 1978, 84, 511-521. [CrossRef]

40. DIN EN ISO 5167-1. In Durchflussmessung von Fluiden mit Drosselgeräten in voll Durchströmten Leitungen mit Kreisquerschnitt-Teil 1: Allgemeine Grundlagen und Anforderungen (ISO 5167-1:2003); Beuth Verlag GmbH: Berlin, Germany, 2003.

41. BG Fachausschuss Chemie. Spürgas-Höchstwerte (SF6) für Abzüge Nach DIN EN 14175. Available online: http:/ / www.bgrci. de/fachwissen-portal/themenspektrum/laboratorien/abzuege/abzuege-nach-din-en-14175/ (accessed on 13 March 2019). 